\title{
The Economics of the Online Advertising Industry
}

\author{
DAVID S. EVANS *
}

LECG

\begin{abstract}
Internet-based technologies are revolutionizing the stodgy $\$ 625$ billion global advertising industry. There are a number of public policy issues to consider. Will a single ad platform emerge or will several remain viable? What are the consequences of alternative market structures for a web economy that is increasingly based on selling eyeballs to advertisers? This article describes the online advertising industry. The industry is populated by a number of multi-sided platforms that facilitate connecting advertisers to viewers. Search-based advertising platforms, the most developed of these, have interesting economic features that result from the combination of keyword bidding by advertisers and single-homing.
\end{abstract}

\section{Introduction}

Online advertising began in 1994 when HotWire sold the first banner ads to several advertisers. ${ }^{1}$ Revenue in the United States grew to an estimated \$7.1 billion in 2001 or about 3.1 percent of overall advertising spending. The dot-com bust destroyed or weakened many of the early online advertising industry players and reduced the demand for online advertising and related services.

The industry regained momentum by 2004 as the business model for "Web 2.0" came together. ${ }^{2}$ A number of businesses such as Advertising.com, Google and ValueClick emerged that facilitated the buying and selling of advertising space on web pages. Many web sites settled on the traditional "free-tv" model: generate traffic by giving away the content and sell that traffic to advertisers. Of the 20 top web sites, based on unique visitors, in the United States, 14 generate the preponderance of their revenues from the sale of

\footnotetext{
* LECG, 350 Massachusetts Ave., Cambridge, MA. 02139. Email: devans@lecg.com The author would like to thank Thomas Eisenmann, Shane Pedersen, Martin Peitz, Greg Sivinski, Daniel Garcia Swartz, Adam Towvim, and, especially, Howard Chang for many helpful insights and discussions and Aditya Bhave, Marina Danilevsky, Melissa DiBella, and Sokol Vako for exceptional research support. The author has benefited from numerous discussions with people in the online advertising industry including, in particular, Scot McLernon and Bruce Jaret, who were previously with CBS Digital Media. Research support was provided by Microsoft, for which the author expresses his gratitude. All opinions and errors are mine alone.

${ }^{1}$ Kaye and Medoff (2001).

2 "Hundreds of Internet companies have emerged since the dot-com crash, looking to capitalize on a resurgent online advertising market. Companies in this new wave - known as Web 2.0 - have focused on online collaboration and sharing among users. They hope to attract millions of users and become the next YouTube, which was acquired by Google Inc. earlier this year for \$1.65 billion." See Wall Street Journal (27 December 2006) "Is 'Web 2.0' Another Bubble?”
} 
advertising inventory - the eyeballs that view space allocated for promotions - to advertisers. $^{3}$ In 2007, advertisers in the United States spent more than \$21 billion advertising on websites, about 7 percent of all U.S. advertising spending. ${ }^{4}$

The portion of advertising that is done online is expected to increase significantly over time as web-based content and services expand and people are able to access the web through more devices such as mobile telephones and televisions. The valuations that the capital markets are placing on businesses related to online advertising are consistent with this prediction. Google has had a nearly five-fold increase in its market value from August 2004 when it was valued at $\$ 29$ billion to $\$ 136$ billion in April 2008. During 2007, several companies in the online advertising market were purchased at multiples of 10-15 times annual revenues. ${ }^{5}$

The online advertising industry burst into the public eye in 2007. Google's skyrocketing stock price and its forays into industries such as word processing software, online payments, and mobile telephones drew significant attention. More than 500 articles on Google appeared in the New York Times, Wall St. Journal and the Financial Times during the year. The U.S. Federal Trade Commission and the European Commission launched in-depth antitrust investigations into Google's acquisition of DoubleClick, which provides software technology and services to online advertisers and publishers. ${ }^{6}$ Privacy concerns also came to the fore in 2007 as consumers, government agencies and the media started focusing on the massive amount of personal data that online advertising companies were storing and using. ${ }^{7}$

This article describes how the online advertising industry works, focusing on several economic aspects of this business. Although the online advertising industry has revolutionized many aspects of an age-old business, it is important to understand, as we present in Section 2, that the new industry has much in common with the old. The unique features of online advertising include the use of Internet-based technologies and data collection mechanisms to target and track specific individuals and to automate the buying and selling of advertising inventory. Like modern finance, online advertising relies heavily on advanced economic and statistical methods. These topics are discussed in Section 3, which focuses on search-based advertising - the most well developed part of the online

\footnotetext{
${ }^{3}$ Of these 14 , five also use a subscription model to supplement revenues. Out of the remaining six, four use the merchant model, one uses the auction model (eBay.com), and one is a not-for-profit (wikipedia.org). ${ }^{4}$ Hallerman (2008). Estimates of advertising spending, especially online advertising spending, should be viewed as indicative.

${ }^{5}$ Google announced in May 2007 that it would purchase DoubleClick for $\$ 3.1$ billion which is more than 10 times DoubleClick's revenues according to one account. Story, L. and M. Helft (14 April 2007) "Google Buys an Online Ad Firm for \$3.1 Billion," New York Times. Microsoft purchased aQuantive at a multiple of about 13. Galli, P. (18 May 2007) "Microsoft's aQuantive Buy Shows Big Ad Plans," eWeek.com. Yahoo paid some $\$ 680$ million for 80 percent share of Right Media which generated about $\$ 35$ million in revenues in 2006. Liedtke, M. (30 April 2007) "Yahoo snaps up Right Media for \$680M," USA Today.

${ }^{6}$ European Commission Press Release (13 November 2007) "Mergers: Commission opens in-depth investigation into Google's proposed take over of DoubleClick"; Google SEC Filing (29 May 2007), "Form 8-K." Also, the United States Senate held hearings on this acquisition. See Senate Judiciary Committee (27 September 2007), "An Examination of the Google-DoubleClick Merger and the Online Advertising Industry: What Are the Risks for Competition and Privacy?" The FTC cleared the transaction on 20 December 2007. See Federal Trade Commission "Statement of Federal Trade Commission concerning Google/DoubleClick: FTC File No. 071-0170" http://www.ftc.gov/os/caselist/0710170/071220statement.pdf.

${ }^{7}$ Ram, V. (28 May 2007) "EU Turns Spotlight on Google," Forbes; Lohr, S. (29 May 2007) "Google Deal Said to Bring U.S. Scrutiny," New York Times; Waters, D. (31 May 2007) "Google Privacy Policy "is Vague'," BBC News.
} 
advertising business to date - and Section 4, which examines online display advertising, a rapidly evolving part of the business that involves advertising on any web sites that draw traffic. The online advertising industry is highly complex, undergoing a series of rapid changes, and could well result in a high degree of concentration, if not monopoly, in the intermediation of advertising inventory and the control of personal data. Section 5 presents concluding remarks, and explains why the online advertising industry will remain at the centre of public policy debate for many years to come.

\section{The advertising business}

Advertising is designed to promote the sale of a product or service. It has been around in some form since ancient times and occurs in many cultures. The business of presenting advertisements to people became enormous during the 20th century with the development of various methods of mass communication and the perfection of the advertiser-supported model for delivering content. Advertising spending worldwide is over $\$ 625$ billion a year, a number that exceeds worldwide spending on wireless voice communication. ${ }^{8}$

\subsection{A brief history}

Outdoor advertisements were some of the earliest methods of promoting sales, with signs appearing in Babylonia as far back as $3000 \mathrm{BC}$. An ad found in the ruins of Pompeii points travelers to a tavern in a nearby town. A key innovation in the history of advertising was the insertion of ads into media that attracted viewers. The first newspaper ad was reported to have occurred in 1672, offering a reward for the return of 12 stolen horses. The Boston News-Letter began carrying ads in $1704 .{ }^{9}$

The advertising industry has developed at least in part as a result of media companies realizing - as web sites have recently - that a profitable business model involves using content to attract viewers and selling access to those viewers to advertisers. The U.S. magazine industry settled on this "two-sided" model in the late 19 th century. ${ }^{10}$ One of the leading publishers dropped its magazine price sharply to increase circulation, and instead earned revenue from selling advertisements. Revenue and profits increased from this pricing innovation. Most magazine publishers quickly followed, and today that is how most earn their profits. The radio industry initially struggled with a subscription-based model, but several stations discovered the power of advertising and the rest quickly followed. Television followed the same path. ${ }^{11}$

Advertising agencies emerged in the mid 19th century as brokers between newspapers and advertisers. The first agency in the United States started in 1841. Its agents bought large amounts of newspaper advertising space at a discounted price and then resold it to advertisers. At first, the advertisers designed the ads and the agency just placed them, but later on advertising agencies started designing the ads and providing other services. The

\footnotetext{
${ }^{8}$ Elliott, S. (4 December 2007) "Forecasters Say Madison Avenue Will Escape a Recession, Just Barely," New York Times. Minton (2007).

${ }^{9}$ Microsoft (2007) "Advertising," Encarta Online Encyclopedia http://encarta.msn.com/encyclopedia 761564279/Advertising.html.

${ }^{10}$ For an introduction to two-sided business models, see Evans and Schmalensee (2007a). The seminal economics paper in this area is Rochet and Tirole (2003).

${ }^{11}$ Evans and Schmalensee, supra note 10; Microsoft Encarta, supra note 9.
} 
business model that eventually developed involved giving creative and marketing services away in return for commission on the media buying.

\subsection{Role of advertising}

Although all advertising is ultimately designed to generate the sales of goods and services, it does so in different ways. Some advertising is designed to generate sales directly by identifying "leads". People who look up a type of service in the yellow pages, for example, are generally interested in purchasing that service. The paid listings and advertisements in the yellow pages are designed to encourage solid sales prospects to patronize the advertiser's business. Other advertising is informative. It provides consumers with information about prices and products, which they can use to make purchasing decisions. Newspaper ads for supermarkets that list sale items and their prices are an example. Still other advertising is about branding or altering people's perceptions about a product or service. The "Visa Is Life" television advertisements are an example of this. The lines between lead-generation, information provision, and branding are blurry. The distinctions are important for the discussion below, however, because online advertising has provided especially innovative technology for generating leads. ${ }^{12}$

\subsection{Pricing and business models}

The most common pricing method in the advertising industry is based on cost per viewer, often expressed in terms of the cost of reaching a thousand viewers (CPM). Newspaper, radio, and television advertisements are typically sold based on estimates of the number of people with certain demographic characteristics who will view an ad that has been placed in one of those media outlets. Television ad rates in the United States, for example, are largely determined by Nielsen Media Research's data on demographics and what is being viewed. Broadcasters and ad agencies negotiate prices based on Nielsen's numbers, and the outcomes of these negotiations in turn determine which programs remain on the air. ${ }^{13}$ Furthermore, contracts between advertisers and TV networks usually include a rating guarantee. Should ratings of the program in which the ad is shown fall short of the agreed level, TV networks would provide extra ad time to the advertisers. ${ }^{14}$

Traditional media that use content to attract viewers have adopted two different models. In the subscription/advertising model, the publisher charges viewers a fee to obtain access to the content, and advertisers a fee to obtain access to the viewers. Many newspapers and magazines follow this model. They then balance the demand from advertisers and subscribers to maximize revenues. Some magazines, for example, The Economist, have adopted reader-friendly strategies with high reader fees but sparse advertising. Others have adopted advertiser-friendly strategies, for example, Vogue, with

\footnotetext{
${ }^{12}$ For a general introduction to the economics of advertising see Bagwell (2007).

${ }^{13}$ Evans, D.S., F.M. Fisher and J.J. McGowan (Autumn 1980) "The Audience Revenue Relationship for Local Broadcast Stations," Bell Journal of Economics, 11: 694-708; Journalism.org (2 November 2006) "Nielsen Starts Watching the Ad Watchers"; Nielsen Media Research "Collecting and Processing the Data" http://www.nielsenmedia.com.

${ }^{14}$ For example, "[I]f NBC Universal [did] not deliver the viewers it [had] promised advertisers, it would have to offer them compensatory commercial time..." See Elliott, S. (13 August 2004) "Olympic-Size TV Audience for the Athens Games?" New York Times. Also "ABC, CBS, NBC, Fox and the CW network sold $\$ 9.3$ billion in prime-time ads for this season. In the process, they sold about 80 percent of their time, holding back some to give advertisers should ratings fall short of guarantees." See James, M. and A. Semuels (12 December 2007) "Lower ratings could pinch TV ads," Los Angeles Times.
} 
lower reader fees and more advertising, some of which makes reading the magazine difficult. In the free-media model, the publishers do not charge viewers for access to the media at all, and in fact try to distribute the media as widely as possible. They earn all of their revenues and profits from the sale of advertisements. Free radio and television have embraced this model in the United States. However, there are many free newspapers and magazines that have adopted the free-TV model. Pay-television and satellite radio have adopted the mixed subscription/advertising model. These different business models are now better understood as a result of the work on multi-sided platforms. ${ }^{15}$

\subsection{The online advertising industry}

The online advertising industry concerns buying and selling advertising space that is accessed by viewers through the Internet. Industry observers often divide the online advertising industry into: (1) "search advertising" that appears on search-results pages; (2) "display advertising" that appears on non-search web pages; (3) classified listings that appear on web sites; and (4) Internet e-mail based advertisements. Table 1 reports U.S. advertising spending for 2006 in these categories and growth between 2002 and 2006.

Search-based advertising accounted for the largest portion with 40 percent followed by display-related advertising with 32 percent in 2006 (of which 22 percent was display advertising, with rich media and sponsorship accounting for the remaining 10 percent). All segments have grown significantly in the last few years with search having the highest growth rate.

In many ways, online advertising is similar to traditional advertising. Publishers use content to attract viewers and then sell advertisers access to those viewers. Advertisers can display text (like classifieds), graphics (like magazines) and video (like television) ads in the space supplied by the publishers. On one level, one can think of the web as just adding more advertising inventory, much like displaying ads on televisions in the back of taxis. Indeed, in some ways the introduction of online advertising was a less radical innovation than the introduction of other media. After all, television enabled advertisers to reach mass audiences with video ads while the web is relying on quite traditional methods of presentation.

Three radical innovations, however, distinguish online from off-line advertising. The first has transformed the service obtained by the advertiser: the Internet provides a highly efficient mechanism for delivering ads to individual users and collecting information for targeting ads to those users. The second has transformed the process of buying and selling advertising space: the Internet has enabled the development of more efficient intermediation markets for advertising - the keyword bidding system used for search and contextual advertising is the most mature example. The third is leading to economies of specialization: traditional publishers provide content for attracting viewers and sell advertising space to advertisers; online publishers are increasingly turning the selling of advertising space over to specialized advertising platforms such as Google or advertising.com.

\footnotetext{
${ }^{15}$ Rochet and Tirole, supra note 10; Anderson and Gabszewicz (2006); Anderson and Coate (2005).
} 


\begin{tabular}{|l|l|l|l|l|l|l|}
\hline & Search & Display & Classifieds & E-mail & Other & Total \\
\hline $\mathbf{2 0 0 2}$ & $\$ 0.90$ & $\$ 3.42$ & $\$ 0.90$ & $\$ 0.24$ & $\$ 0.54$ & $\$ 6.0$ \\
\hline $\mathbf{2 0 0 3}$ & $\$ 2.56$ & $\$ 2.99$ & $\$ 1.24$ & $\$ 0.22$ & $\$ 0.29$ & $\$ 7.3$ \\
\hline $\mathbf{2 0 0 4}$ & $\$ 3.74$ & $\$ 3.65$ & $\$ 1.73$ & $\$ 0.19$ & $\$ 0.29$ & $\$ 9.6$ \\
\hline $\mathbf{2 0 0 5}$ & $\$ 5.13$ & $\$ 4.25$ & $\$ 2.13$ & $\$ 0.25$ & $\$ 0.75$ & $\$ 12.5$ \\
\hline $\mathbf{2 0 0 6}$ & $\$ 6.76$ & $\$ 5.41$ & $\$ 3.04$ & $\$ 0.34$ & $\$ 1.35$ & $\$ 16.9$ \\
\hline $\begin{array}{l}\text { \% Change: } \\
\text { 2002-2006 }\end{array}$ & $651 \%$ & $58 \%$ & $238 \%$ & $41 \%$ & $150 \%$ & $182 \%$ \\
\hline
\end{tabular}

Table 1. US online ad spending, 2002 - 2006 (Billions). Display includes display ads, rich media, ${ }^{16}$ and sponsorship.

Source: $I A B$ (2003), IAB (2004), IAB (2005), IAB (2006), IAB (2007).

As more advertising moves to Internet-connected devices, these innovations will dramatically alter the advertising ecosystem. These innovations are mainly affecting search and display advertising, which are the focus of this article.

\section{$3 \quad$ Advertising on search results pages}

When you enter a search query using one of the commercial search engines, you will often see the web page divided into up to three areas as shown in Figure 1.

The left-hand side of the screen displays the "organic search results". These are based on an index of the world-wide-web maintained by the search engine provider and selected based on algorithms that rank their likely relevance to the search query term(s). The righthand side of the screen displays "paid search results", which are listings sold by the search engine provider to advertisers. The top-left-hand side of the screen above the organic search results may also include paid search results for some search engines. A search query may generate a series of pages of search results, and each page may have ads on the righthand side if there have been buyers for the space.

\footnotetext{
${ }^{16}$ As per the IAB report, 'rich media' comprises "advertisements that incorporate animation, sound, and/or interactivity in any format. It can be used either singularly or in combination with the following technologies: sound, Flash, and with programming languages such as Java, JavaScript, and DHTML. It is deployed via standard Web and wireless applications including e-mail, static (for example html) and dynamic (for example asp) Web pages, and may appear in ad formats such as banners, buttons, and interstitials. Interstitials are included in the rich media category and represent full - or partial-page text and image serverpush advertisements which appear in the transition between two pages of content. Forms of interstitials can include splash screens, page takeovers and pop-up windows.” See IAB (2007).
} 


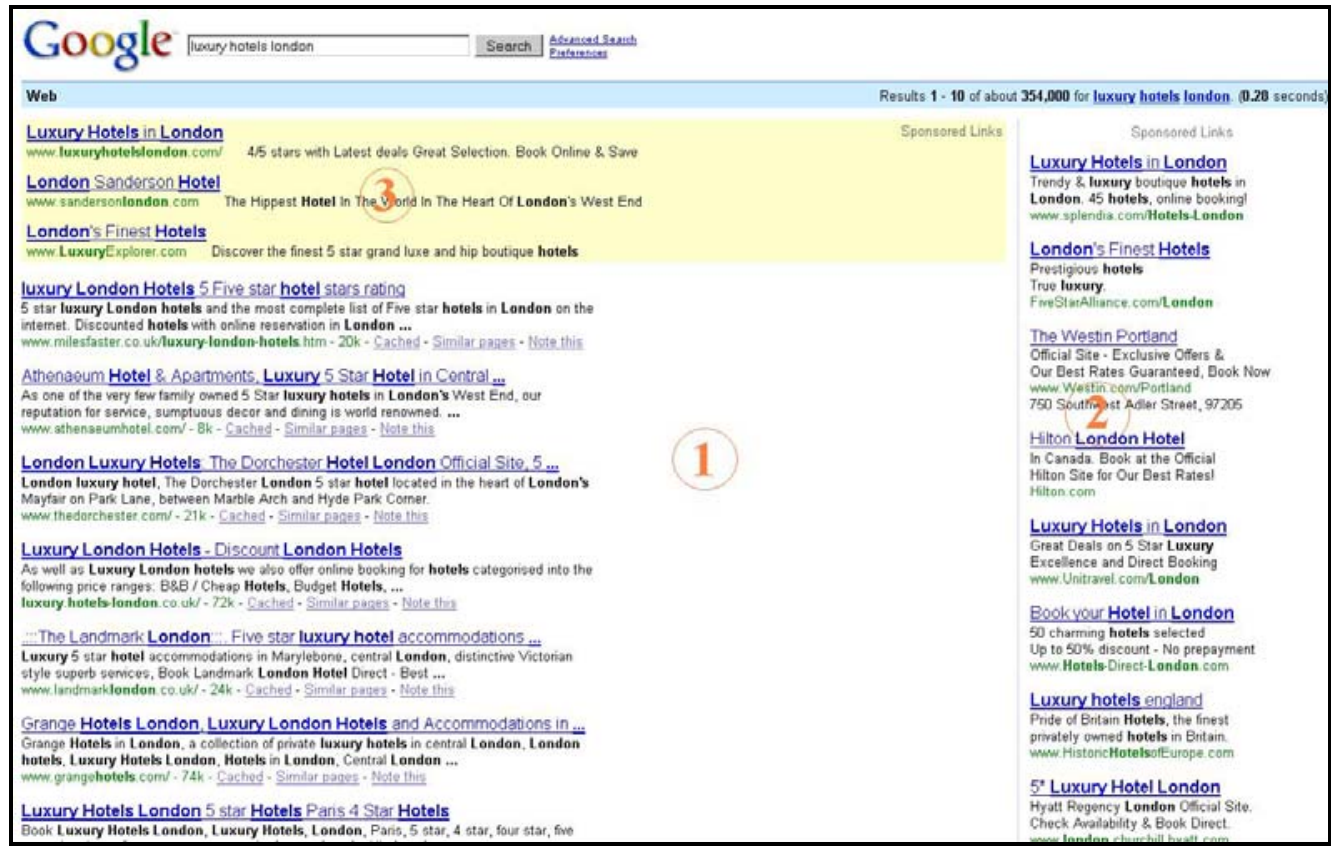

Figure 1. A search on Google for "luxury hotels London" shows the resulting webpage divided into three areas: 1) organic search results, 2) paid search results, and 3) more paid search results.

A "search-based advertising platform" (search-ad platform for brevity) attracts viewers to its pages largely by displaying the organic search results from its search engine. It allocates a portion of the page for the purpose of selling advertising space, and divides this space into slots (there are typically 8-10 per page) which it sells to advertisers. There are two key technological innovations that underlie this process, both of which depend on advanced economic and mathematical methods, and which ultimately help determine the nature of the market structure.

\subsection{Technological underpinnings of search-based advertising}

Search-ad platforms use a "keyword bidding system". Advertisers bid on search query terms known as keywords. They can bid on individual keywords as well as combinations such as "hotel", "hotel Boston", "luxury hotel Boston", and "hotel Beacon Hill". ${ }^{17}$ The major commercial search-ad platforms use a second-price auction with a reserve price for this auction. ${ }^{18}$ The price is based on the charge for each time an Internet user clicks on the ad ("cost-per-click" or CPC). All else equal, a higher bid price will secure a higher slot (one closer to the first slot at the top of the first page).

\footnotetext{
${ }^{17}$ When users bid on keywords, those keywords are set to a certain match option. These options include a broad match (which displays the ad when customers search for words in the keyword list in any order and possibly with other terms), a phrase match (which displays the ad when a customer's search query includes all keywords in the exact order given, even if the query has other terms that precede or follow the phrase), and an exact match (which makes an ad eligible when a search includes the specific keyword or phrase, in order, and without any other terms in the query). Negative keywords can also be added so that an ad will not be displayed if a search query contains a negative keyword.

${ }^{18}$ See Edelman, Ostrovsky and Schwarz (2007); Microsoft "What's the Cost?" http://advertising.microsoft.com/search-advertising/cost. Also see Varian (2006).
} 
The bid itself does not, however, necessarily determine the slot that an ad is placed in, which brings us to the second technological innovation. The search-ad platforms want to maximize the revenue they receive from selling slots. Since they have chosen to charge based on CPC, they need to take into account the number of clicks that an ad will receive. They may earn more profits by putting ads with lower CPC bids in higher slots if doing so generates more clicks than ads with higher CPC bids. To maximize revenue the search-ad platform therefore needs to estimate the "click-through-rate" (CTR) for a search ad bid and allocate the slots to bidders to maximize revenue. In addition, the platform must consider the ultimate relevance of ads to viewers. An ad that is good at attracting clicks but does not result in sales to users will likely leave users dissatisfied with seeing less relevant ads and advertisers dissatisfied with having paid for ads that did not lead to sales. Google does this by estimating a "quality score" for each bid that reflects the expected CTR and the relevance of the ad to a searcher. Estimating these types of quality measures is especially difficult for advertisers and keyword combinations for which the search-ad platform has no experience. $^{19}$

The keyword bidding process and the quality score algorithm together determine both the CPC advertisers pay and the slots they receive. Search-ad platforms sometimes provide bidders guidance on what they would have to pay to get particular slots. For example, Google estimates that bidders would have to pay an estimated $\$ 3.04$ to get the third slot for "luxury hotels London" and $\$ 0.05$ to get the third slot for "competition economists". 20

These technologies affect the market structure in two ways as we will see below. First, the keyword bidding system can give rise to demand-side scale economies. There is essentially a liquidity effect arising from larger platforms having thicker markets for keywords. Second, platforms that have superior technologies can earn more from additional searchers and therefore bid more for traffic, thereby accelerating positive feedback effects. Before discussing these features in more detail we survey the current state of competition in the search-based advertising business.

\subsection{Market structure of search-based advertising}

Because search-based advertising is two-sided, one needs to examine the position of search-ad platforms on their ability to generate search traffic, as well as their ability to sell that search traffic to advertisers. Considering these two dimensions, we begin by looking at the current structure of the business and its evolution over time.

\footnotetext{
${ }^{19}$ The exact methodology of each search-ad platform and the precise dates of implementation are not public but there have been significant differences across platforms. Google appears to have had a quality score since at least August 2005. See Google AdWords, "A new addition to the Quality Score" http://adwords.blogspot.com/2005/12/new-addition-to-quality-score.html. Yahoo does not appear to have relied on these quality measures until its Panama platform was implemented in February 2007. Microsoft used Yahoo's platform until it launched its own search-ad platform in the United States in May 2006. Microsoft's platform appears to have always had some form of quality scoring. See MSDN Blogs, "Best Practice Makes Perfect-Part One" http://blogs.msdn.com/adcenter/archive/2006/08/23/715430.aspx, discussing an "enhancement" to "existing guidelines around relevance and quality" in April 2007. There may of course still be significant differences in the effectiveness of the quality scores across platforms.

${ }^{20}$ See Varian, supra note 18 , for an analysis of the equilibrium bidding for slots. Also see Schwarz and Sonin (2005).
} 


\subsubsection{Market structure in $\mathbf{2} 2007$}

In the United States, the search-based advertising business has three major players, as well as some fringe firms. The shares of search traffic are reported in Table 2. There is a consensus in the industry that the larger platforms realize higher revenue per search than small platforms. ${ }^{21}$ Consequently, the shares based on revenue are more highly skewed than the shares based on search traffic.

\begin{tabular}{|l|l|l|l|l|}
\hline Platform & $\begin{array}{l}\text { Share of } \\
\text { Search Traffic, } \\
\text { Dec. 2004 }\end{array}$ & $\begin{array}{l}\text { Share of } \\
\text { Search Traffic, } \\
\text { Dec. 2005 }\end{array}$ & $\begin{array}{l}\text { Share of } \\
\text { Search Traffic, } \\
\text { Dec. 2006 }\end{array}$ & $\begin{array}{l}\text { Share of } \\
\text { Search Traffic, } \\
\text { Dec. 2007 }\end{array}$ \\
\hline Google & $35.6 \%$ & $40.5 \%$ & $50.8 \%$ & $61.3 \%$ \\
\hline Yahoo & $32.7 \%$ & $29.9 \%$ & $26.6 \%$ & $20.2 \%$ \\
\hline MSN & $16.7 \%$ & $14.5 \%$ & $9.4 \%$ & $8.2 \%$ \\
\hline $\begin{array}{l}\text { Time Warner } \\
\text { / AOL }\end{array}$ & $9.6 \%$ & $8.7 \%$ & $9.1 \%$ & $6.7 \%$ \\
\hline Ask & $5.4 \%$ & $6.4 \%$ & $4.2 \%$ & $3.6 \%$ \\
\hline HHI & $\mathbf{2 , 7 3 5}$ & $\mathbf{2 , 8 6 4}$ & $\mathbf{3 , 4 7 3}$ & $\mathbf{4 , 2 9 1}$ \\
\hline
\end{tabular}

Table 2. US search engine share by search queries.

Note: Shares are calculated from searches conducted on the above five web properties only. The share for the Time Warner Network may be slightly overstated as searches conducted within its websites, such as MapQuest, are included. The HHI estimates are slightly overstated as only the shares of the top 5 firms are considered, but the trend in the estimated HHIs should be indicative of that of the actual HHIs. Source: Dec. 2004 - Dec. 2005: comScore (January 2007) "comScore MediaMetrix [custom query prepared by comScore]". Dec. 2006 - Dec. 2007: comScore (December 2006 and December 2007) "comScore MediaMetrix, qSearch 2.0 Key Measures Report”.

The industry is highly concentrated with an HHI of over 3,000 based on search traffic and higher based on advertising revenue. ${ }^{22}$ The size distribution of firms is also highly skewed. Measured by 2006 advertising revenue, the largest platform (Google) is nearly three times as large as the second-largest platform (Yahoo). ${ }^{23}$ The rankings by search traffic are slightly less skewed.

Most consumers have, or can easily obtain a search engine. The typical computer comes with a search toolbar preinstalled in the browser. A 2007 study examined PCs sold by OEMs who accounted for at least one percent of U.S. home and small office sales in

\footnotetext{
${ }^{21}$ We discuss evidence on this below.

${ }^{22}$ The HHI is a standard measure of concentration used in merger analysis. It ranges from a high of 10,000 for a pure monopoly to 0 for a perfectly competitive industry. Industries with HHIs in excess of 1,800 are considered to be sufficiently concentrated that US antitrust authorities look closely at mergers in these industries. See Federal Trade Commission, “1992 Horizontal Merger Guidelines [with April 8, 1997, Revisions to Section 4 on Efficiencies]" http://www.ftc.gov/bc/docs/horizmer.shtm.

${ }^{23}$ Neither Google nor Yahoo break out their search advertising revenues from their contextual advertising revenues, so this ratio is for both search and contextual advertising combined. Google's worldwide 2006 search and contextual advertising revenue is estimated at $\$ 10.5$ billion and Yahoo's worldwide 2006 search and contextual advertising revenue is estimated at \$3.7 billion. Estimates come from Lehman Brothers (2007). The Google to Yahoo ratio based on these revenue figures is about 2.9, while the ratio for search traffic of Google to Yahoo in November 2007 was 1.7.
} 
2006. All of the PCs had a search toolbar preinstalled, with Google having the greatest number of installations. ${ }^{24}$ It is also easy to add additional search toolbars, such as the Windows Live Toolbar and the Yahoo! Toolbar. Thus, consumers can use multiple search engines if they want and it is relatively easy to do so. ${ }^{25}$ Looking among users of Google, Yahoo and Microsoft's search engines over the course of one month, more than a third used more than one search engine. But the extent of multihoming differed significantly across platforms-only about 40 percent of users of Google used one of the two other search engines over the course of a month, while the comparable figures were over 70 percent for Yahoo users and 80 percent for Microsoft users. ${ }^{26}$ That could come from their using multiple engines for the same search, or different engines for different searches. ${ }^{27}$ Nevertheless, most people I have asked (acquaintances plus several polls of audiences) use a single search engine primarily and tend to use other ones for idiosyncratic reasons. Moreover, only rarely in my experience do people use multiple search engines for a single query. Thus in the remainder of the paper I will assume that users "single-home" on a search-ad platform using the terminology from the two-sided platform literature.

On the advertiser side, multihoming on search-ad platforms varies significantly across advertisers. Although representative data are not publicly available, discussions I have had with industry participants indicate that all of the largest advertisers, such as Amazon and WalMart, will advertise on all of the three major search-ad platforms. The value of a click from one search engine is independent of the value of a click from another search engine since these are different lead opportunities if people single-home for a given search. All else equal, there is therefore no reason to pay for clicks only from a single search engine. ${ }^{28}$ The major incentive not to use an additional search-ad platform is the cost of setting up that platform and monitoring ad campaigns on it. Those costs, which are largely fixed, will be amortized over fewer clicks on a smaller search-ad platform. Discussions I have had with industry participants indicate that medium and small search advertisers will use Google uniformly but are less likely to use Yahoo and, especially, Microsoft. In addition, advertisers both large and small that do use multiple platforms will tend to place fewer bids on the smaller platforms. In aggregate, this leads to significantly more bids on Google than

\footnotetext{
${ }^{24}$ Google was found on three of the seven PCs, Yahoo! on two, AOL on one, and Windows Live on one.

${ }^{25}$ Google has programmed its search toolbar to make it difficult for users to easily switch. When a user attempts to change the default search, Google blocks the switch by default and briefly displays a notification in the bottom right corner of the screen. If the user clicks on the notification before it disappears, a popup window provides the user with the option to disable Google's "default search protection". This does not appear to be the case for Yahoo or Microsoft.

${ }^{26}$ comScore (January 2008) "comScore MediaMetrix, Digital Calculator Report". Note that the extent of multihoming for users overall is lower than for any individual platform because a given user that multihomes between say Google and Yahoo will be counted as multihoming twice in the individual platform multihoming figures and only once in the overall figure.

${ }^{27}$ There are also "meta" search engines such as Excite, Dogpile, and Metacrawler that deliver results from several engines. These are not widely used as of 2007.

${ }^{28}$ This statement is not meant to suggest that there are no substitution possibilities from the standpoint of the advertiser. Search generates leads which can translate into sales with some probability. However, advertisers have a number of different methods available to them to generate leads of which search-based advertising is only one way. We would expect that advertisers will invest in different methods of lead generation up to the point where the returns are equalized at the margin. They may therefore increase their investment in platforms that have lower CPCs relative to their investment in platforms that have higher CPCs for given keywords.
} 
on Yahoo or Microsoft. ${ }^{29}$ We discuss the fixed costs of maintaining search advertising campaigns in more detail below because they can have important implications for positive feedback effects.

\subsubsection{Evolution of market structure}

Search-based advertising started in 1995 when Infoseek, one of the earlier search engines for the web, began to target banner ads in their system to the keywords users entered. The CPC model was introduced in a deal Proctor and Gamble struck with Yahoo in $1996 .{ }^{30}$ In 1998, GoTo.com introduced the first clearly marked ads alongside organic search results and charged advertisers for these ads based on CPC. GoTo.com became Overture which in turn became Yahoo's ad search platform. Other search engines quickly followed this model. Google launched AdWords in 2000, which was similar to GoTo but distinguished the ads from the organic search results more clearly. ${ }^{31}$

Thus far, there have been two leaders in search-based advertising. Although Infoseek started the search-ad business in 1995, no real leader emerged until 1999. Yahoo held the top spot from 1999 to 2002. Google achieved a higher share than Yahoo of search traffic in the U.S. in 2003 and has held the lead ever since. Google's page rank algorithm, used to decide which results to present to a searcher, has been described as follows ${ }^{32}$ :

"It is a crucial part of Google's inner sanctum, a department called 'search quality' that the company treats like a state secret."

Table 3 reports the first, second and third players in the US from 1999 to 2007 (the table also indicates whether the firm used its own search engine (S) and ad platform (A) technologies or whether those were outsourced). ${ }^{33}$

\footnotetext{
${ }^{29}$ Pay Per Click Journal (27 October 2007) "Google AdWords Vs. Microsoft AdCenter," http://payperclickjournal.com/google-adwords-vs-microsoft-adcenter/10/27/2007/; Blodget,H. (2 October 2007) “The Real Reason Yahoo's Revenue Per Search Stinks,” Silicon Alley Insider, http://www.alleyinsider.com/2007/10/the-real-reason.html.

${ }^{30}$ See Yahoo Investor Relations (8 May 1996) "Yahoo and Procter \& Gamble Develop Interactive Traffic Building Promotion"; See also Google and Yahoo News and Press Releases.

${ }^{31}$ For a discussion of the evolution of search-based advertising see Battelle (2005), in particular Chapter 3; also see Cho, M. et al (2005).

${ }^{32}$ Hansell, S. (3 June 2007) "Google Keeps Tweaking Its Search Engine,” New York Times. Google has described PageRank, its system for ranking web pages, as the "heart" of its software. See Google (downloaded December 2007) “Our Search: Google Technology,” http://www.google.com/technology/. ${ }^{33}$ An interesting area of exploration concerns differences in market structure internationally. Google is the dominant search provider globally and in many countries. It has reportedly more than a 90 percent share of search traffic in Argentina, Brazil, and Spain. However, it is not the largest player in China where Baidu has 61 percent of the search traffic or Japan where Yahoo has 50 percent.
} 


\begin{tabular}{|c|c|c|c|c|c|c|c|c|c|}
\hline Place & 1999 & 2000 & 2001 & 2002 & 2003 & 2004 & 2005 & 2006 & 2007 \\
\hline $1 \mathrm{st}$ & $\begin{array}{l}\text { Yahoo } \\
\text { (S: Inktomi } \\
\text { A: Own) }\end{array}$ & $\begin{array}{l}\text { Yahoo } \\
\text { (S: Google } \\
\text { A: Own) }\end{array}$ & $\begin{array}{l}\text { Yahoo } \\
\text { (S: Google: } \\
\text { A: Own) }\end{array}$ & $\begin{array}{l}\text { Yahoo } \\
\text { (S: Google, } \\
\text { A: } \\
\text { Overture) }\end{array}$ & $\begin{array}{l}\text { Google } \\
\text { (S: Own, } \\
\text { A: Own) }\end{array}$ & $\begin{array}{l}\text { Google } \\
\text { (S: Own, } \\
\text { A: Own) }\end{array}$ & $\begin{array}{l}\text { Google } \\
\text { (S: Own, } \\
\text { A: Own) }\end{array}$ & $\begin{array}{l}\text { Google } \\
\text { (S: Own, } \\
\text { A: Own) }\end{array}$ & $\begin{array}{l}\text { Google } \\
\text { (S: Own, } \\
\text { A: Own) }\end{array}$ \\
\hline 2nd & $\begin{array}{l}\text { AltaVista } \\
\text { (S: Own } \\
\text { A: } \\
\text { DoubleClick) }\end{array}$ & $\begin{array}{l}\text { AltaVista } \\
\text { (S: Own, } \\
\text { A: } \\
\text { DoubleClick) }\end{array}$ & $\begin{array}{l}\text { Microsoft (S: } \\
\text { Inktomi, } \\
\text { A: Overture) }\end{array}$ & $\begin{array}{l}\text { Google } \\
\text { (S: Own, } \\
\text { A: Own) }\end{array}$ & $\begin{array}{l}\text { Yahoo } \\
\text { (S: Google, } \\
\text { A: Own) }\end{array}$ & $\begin{array}{l}\text { Yahoo } \\
\text { (S: Own, } \\
\text { A: Own) }\end{array}$ & $\begin{array}{l}\text { Yahoo } \\
\text { (S: Own, } \\
\text { A: Own) }\end{array}$ & $\begin{array}{l}\text { Yahoo } \\
\text { (S: Own, } \\
\text { A: Own) }\end{array}$ & $\begin{array}{l}\text { Yahoo } \\
\text { (S: Own, } \\
\text { A: Own) }\end{array}$ \\
\hline 3rd & $\begin{array}{l}\text { Excite } \\
\text { (S: Own, } \\
\text { A: Excite's } \\
\text { MatchLogic) }\end{array}$ & $\begin{array}{l}\text { Lycos } \\
\text { (S: Fast } \\
\text { Search \& } \\
\text { Transfer } \\
\text { A: Own) }\end{array}$ & $\begin{array}{l}\text { Google } \\
\text { (S: Own, } \\
\text { A: Own) }\end{array}$ & $\begin{array}{l}\text { Microsoft } \\
\text { (S: } \\
\text { Inktomi, } \\
\text { A: } \\
\text { Overture) }\end{array}$ & $\begin{array}{l}\text { Microsoft } \\
\text { (S: Yahoo's } \\
\text { Inktomi, } \\
\text { A: Yahoo's } \\
\text { Overture) }\end{array}$ & $\begin{array}{l}\text { Microsoft } \\
\text { (S: Yahoo's } \\
\text { Inktomi, } \\
\text { A: Yahoo's } \\
\text { Overture) }\end{array}$ & $\begin{array}{l}\text { Microsoft } \\
\text { (S: Own, } \\
\text { A: } \\
\text { Yahoo's } \\
\text { Overture) }\end{array}$ & $\begin{array}{l}\text { Microsoft } \\
\text { (S: Own, } \\
\text { A: Own) }\end{array}$ & $\begin{array}{l}\text { Microsoft } \\
\text { (S: Own, } \\
\text { A: Own) }\end{array}$ \\
\hline
\end{tabular}

Table 3. Leaders in search in the US by traffic. Search website (S: Search technology powering search website, A: Ad platform)

Note: Yahoo acquired Inktomi in 2003; In 1999 and 2000, AltaVista used DoubleClick for banner ads (not ads matched to user search queries). Source: Data for years 1999-2003 compiled from the following trade press articles: Fridman, S. (22 December 1999) "Yahoo's Popularity Continues Strong-Report," Newsbytes New Network; PR Newswire (12 July 2000) "AltaVista Climbs in Search Referrals"; Agence France-Press (30 May 2001) "Yahoo Still on Top in Portal Battle, but MSN Creeping Up"; Agence France-Presse (30 April 2002) "Google Challenging Yahoo as top Global Internet Search Engine: Study"; comScore Press Release (28 April 2003) "comScore MediaMetrix Launches Breakthrough System to track Actual Consumer Search Queries"; Hansell, S. (31 January 2005) "Search Sites Play a Game of Constant Catch-Up," New York Times. Data for years 2004-2005 from Hallerman (2006). Data for years 2006-2007 compiled from comScore reports.

It is useful to focus on the industry since the dot.com bust which marked the collapse of many of the early startups and the emergence of the advertising-supported Web 2.0 industry. Since that time the search-based advertising industry has become increasingly concentrated as Google has outdistanced its rivals. The gap between Google and rest of the search firms has increased substantially - the ratio of the largest firm (Google) to the next largest (Yahoo) has increased from 1.3 to 3.1 over the same period. Table 4 reports the growth in search traffic and advertising revenue from 2001 to 2007.

\begin{tabular}{|l|c|c|c|c|c|c|c|c|}
\hline & $\mathbf{2 0 0 0}$ & $\mathbf{2 0 0 1}$ & $\mathbf{2 0 0 2}$ & $\mathbf{2 0 0 3}$ & $\mathbf{2 0 0 4}$ & $\mathbf{2 0 0 5}$ & $\mathbf{2 0 0 6}$ & $\mathbf{2 0 0 7 E}$ \\
\hline $\begin{array}{l}\text { US Search traffic } \\
\text { (billion queries) }\end{array}$ & $\mathrm{n} / \mathrm{a}$ & $\mathrm{n} / \mathrm{a}$ & $\mathrm{n} / \mathrm{a}$ & $\mathrm{n} / \mathrm{a}$ & 49.0 & 57.5 & 68.0 & 86.4 \\
\hline $\begin{array}{l}\text { US paid search } \\
\text { revenue (\$ millions) }\end{array}$ & $\$ 109$ & $\$ 299$ & $\$ 927$ & $\$ 2,544$ & $\$ 3,850$ & $\$ 5,142$ & $\$ 6,970$ & $\$ 8,288$ \\
\hline
\end{tabular}

Table 4. Growth in search traffic and paid-search revenue in the US, 2001-2007

Note: The 2007 revenue figure is an estimate. Source: US Search Traffic comes from comScore. Source for US Paid Search Revenue: Hallerman (2007). 
In the US, Google has exceeded the growth rates of the next two largest platforms in search in 7 of the last 10 quarters and in revenue in 9 of the last 10 quarters (through the second quarter of 2007).

Google's high share combined with trends indicating that its lead is expanding raise several interesting economic questions: is search-based advertising subject to winner-takeall competition; how easily can more efficient providers displace the incumbent; and to what extent can differentiation on either platform side permit viable competition among several platforms? We turn to these questions next.

\subsection{Economic factors affecting two-sided market structure}

In many ways, search-ad platforms are subject to the same economic considerations as traditional media platforms. They are two-sided businesses based on using bait to attract eyeballs and selling access to those eyeballs to advertisers. However, several features of the technologies underlying search-ad platforms give rise to unique features.

\subsubsection{Pricing of keywords}

Consumers appear, at least based on anecdotal evidence, to use a single platform for a search query. ${ }^{34}$ This is akin to consumers who use a single yellow pages directory for looking up merchants. Advertisers often use multiple search-ad platforms just as they put ads for the same product in magazines that are likely to reach different consumers, such as Vogue and Popular Mechanics. As a result of these facts, market forces do not necessarily lead to the same CPC for a given keyword across search-ad platforms. Neither consumers nor advertisers are making marginal substitution decisions between a given keyword on different platforms. If the CPC for "flat panel televisions in Chicago" was higher on platform 1 than on platform 2, a Chicago television retailer would still use both platforms so long as the CPC was worth the value of the lead generated. ${ }^{35}$

The CPC is ultimately determined by the keyword bidding auction on each platform. Those auctions could result in similar CPCs for given query terms if there were the same bidders, the auction rules were similar, and the values of leads for different platforms were similar. We would expect, as noted above, that platforms that attract fewer bidders for keywords would tend to have lower CPCs for those keywords. We would also expect that platforms that have less efficient auctions, or generate less valuable leads, would have lower CPCs for given keywords.

In fact, there are significant differences in CPCs for keywords across the search-ad platforms. None of the platforms reports these measures, but industry estimates generally

\footnotetext{
${ }^{34}$ There would not seem to be any economic or technological obstacle to consumers using multiple search engines. They are most likely to use the search engine that they expect will provide the best search results which may be some combination of organic results and ads. However, it would seem possible that a market structure could arise with differentiated platforms in which consumers find it useful to rely on several platforms or in which they have greater incentives to use a meta-search platform that combines results from several platforms. Therefore, the existence of single-homing may be endogenously determined by the market structure.

${ }^{35}$ In reality, there are a variety of ways to generate leads, beyond search-ad platforms, and there may be some substitution between these different methods. Moreover, there may be diminishing returns to the value of leads for a variety of reasons including diseconomies of scale in production and distribution.
} 
place Google significantly above Yahoo. One estimate places Google's worldwide CPC at around \$2.00, nearly three times its estimate of Yahoo's CPC of around $\$ 0.75 .^{36}$

\subsubsection{The role of indirect network effects}

It may appear that indirect network effects are insignificant for search-ad platforms, if they are present at all. ${ }^{37}$ An advertiser only pays when a consumer clicks on his ad. That value does not depend on whether any other consumer on the platform clicks on the ad. The advertiser should therefore be indifferent to using a platform with few or many searchers so long as the value exceeds the cost of each click the advertiser gets. It may appear that searchers do not benefit in any obvious way from other searchers. So long as they obtain the information they are looking for, they do not care whether the search provider has many or few searchers. They probably value search-ad platforms that have more ads. But given that advertisers are indifferent, the density of ads on search pages should not vary depending on the number of searches. This view, however, ignores key features of transaction platforms that would appear to lead to strong indirect network effects.

Search-ad platforms are similar to other transaction platforms that seek to match buyers with sellers and consummate trades. With more buyers, there is a higher likelihood that a seller will find a suitable match that will lead to a beneficial sale, and with more sellers, there is a higher likelihood that a buyer will find a suitable match that will lead to a beneficial purchase. The importance of "liquidity" - the volume of buyers and sellers that could reach mutually profitable trades - is well documented for exchanges. ${ }^{38}$ Without enough liquidity, markets are too thin and unsustainable.

In the case of search-ad platforms, the advertisers are the buyers of access to Internet users while the searchers are selling that access through the ad search platform. More advertisers and more searchers increase the likelihood of profitable matches given that advertisers and searchers are heterogeneous. It is useful to consider why in more detail.

\footnotetext{
${ }^{36}$ See Bear Stearns (2007). Other estimates of revenue per search (RPS), which is equal to the CPC times the CTR for each search (not the CTR for each advertiser), place Google substantially above Yahoo. Mark Mahaney, an analyst in Citigroup, estimated that in 2006 Google made 4.5 cents to 5 cents on every search, while Yahoo generated only 2.5 cents to 3 cents a search. See Helft, M. (5 February 2007) "A Long-Delayed Ad System Has Yahoo Crossing Its Fingers," New York Times; Caris \& Co. analyst Tim Boyd estimates that Yahoo made on average between $10 \phi$ and $11 \phi$ per search in 2006, and Google made between $19 \phi$ and $21 \phi$ per search. See Holahan, C. (26 December 2006) “Why Yahoo's Panama Won’t Be Enough,” BusinessWeek; Justin Post, an analyst with Merrill Lynch, estimated that in 2006, each US search generates $4 \notin$ for Yahoo and $11 \notin$ for Google. See Hershey Jr., R.D. (19 November 2006) "Sunny and Gloomy Signs at a Web Crossroads," New York Times; A recent article states that most analysts estimate that Yahoo!'s RPS is about 30 percent less than Google's. See Blodget, H. (2 October 2007) "The Real Reason Yahoo's Revenue Per Search Stinks," Silicon Alley Insider. The differences between these estimates is likely due to whether one looks at searches only within the U.S. or worldwide, and whether one looks at only searches for which there are ads or all searches. But within each estimate, Google is placed significantly above Yahoo.

${ }^{37}$ Although search-ad platforms have to make investments in developing search engines and other technologies, it does not appear that there are significant scale economies that would, by themselves, limit the market to one or just a few players. Search-ad platforms are readily scalable by adding servers and communication. Eisenmann estimates that a search-based advertising platform could break even with about 7.5 percent of the global market. See Eisenmann (2007).

${ }^{38}$ See, for example, Garbade and Silber (1979); See also Economides (1993).
} 
Searchers obtain more relevant ads when there are more advertisers. ${ }^{39}$ Suppose an individual is in Germany and needs a SIM card. She types "Germany SIM cards" into Google. On September 26, 2007 she would have seen ten ads, of which eight were directly relevant to her query. If she typed the same query into the smaller MSN search engine on that same day, she would have seen eight ads of which two were directly relevant to her query. That phenomenon is general: search-ad platforms with more advertisers will generally deliver more relevant ads to the searcher; that statement is particularly true for less common keyword combinations, for which there is a thinner advertising market. Since many searchers are looking to buy things, the larger platform is more valuable to them and they are therefore more likely to use the larger platform all else equal. ${ }^{40}$ (In addition, each searcher benefits from other searchers' queries because the search engine captures information that makes search results more relevant to subsequent searches.)

Advertisers also value more searchers. Consider an advertiser that earns $\$ 50$ per unit on the sale of widgets. It has access to platform 1 and platform 2 where the first platform has 10 times as many searchers as the second. On average, every click generates a sale 20 percent of the time. Suppose that it pays $\$ 0.50$ per click to obtain the 3rd slot on each platform. Platform 1 sends 200 clicks per week generating 40 sales and platform 2 sends 20 clicks per week generating 4 sales. Then the advertiser earns $\$ 2000$ in revenue per week from its campaign on platform 1 for which it pays $\$ 100$ and earns a profit of $\$ 1900$; it earns $\$ 200$ in revenue per week from its campaign on platform 2, for which it pays $\$ 10$ and earns a profit of $\$ 190$. The advertiser therefore values access to the large platform more than it values access to the small platform, even though it does not value a click or a searcher on one more than the other. ${ }^{41}$

The existence of fixed costs, together with the difference in platform value documented above, may have an effect on the economics of the search-ad platforms, given the CPC pricing structure, especially for smaller platforms. Advertisers incur two costs of running campaigns that are independent of the number of clicks. First, they incur costs of setting up the platform, installing software, and learning how to use it. ${ }^{42}$ Consequently, the advertiser must exceed a minimal volume of advertising (or more specifically, a minimal level of incremental profits) from this campaign before contracting with another search-ad platform. Platform set-up costs discourage smaller advertisers from joining smaller

\footnotetext{
${ }^{39}$ Many searchers are looking to buy something and therefore may value relevant advertising. It has been reported that about 40 percent of search queries involve potential commercial transactions. See Eisenmann, supra note 37; See also Dai, et al (2006) "Detecting Online Commercial Intention,” World Wide Web Conference, Edinburgh, Scotland.

${ }^{40}$ Search engines typically capture data on searches and accumulate this over time. See Godoy, M. (20 January 2006) “Google Records Subpoena Raises Privacy Fears," NPR.org. They use this information to improve the ability of the search engine to deliver relevant results. Some studies have found that there are not significant differences in the quality of search results across the major platforms despite the extreme differences in the number of searchers. Thus, it would appear that direct network effects from search are limited. However, search and click-through histories enable search-ad platforms to estimate CTRs better and therefore gives rise to another potentially significant scale effect.

${ }^{41}$ This statement is true except for the situation in which it pays its maximum value per click of $\$ 10$. Then it earns zero profit from either platform and is indifferent between them. While the second-price auction in theory is designed to get bidders to pay their maximum values, in reality, it is will not do so perfectly and we disregard this extreme situation.

${ }^{42}$ There is also an activation fee for the major search-ad platforms. Google and Microsoft each charge \$5; Yahoo has no fee for the "Self Serve" version, but charges \$199 for an assisted setup.
} 
platforms. As discussed above, many smaller advertisers advertise only on Google or only on Google and Yahoo.

Second, advertisers incur costs of running a campaign on keywords. They have to make decisions on the bids and monitor the performance of the campaign. ${ }^{43}$ These tasks generally cannot be automated fully and therefore require humans. Thus, the advertiser must exceed a minimal volume of clicks on a campaign before mounting it on an ad platform that has been set up. To take the example above, if it cost $\$ 200$ per week to monitor a campaign for widgets the advertiser would run the campaign on platform 1 but not platform 2. Therefore, campaign monitoring costs also discourage advertisers from mounting campaigns on platforms that have fewer search queries. As discussed above, even larger advertisers will tend to maintain smaller campaigns on the smaller search-ad platforms.

These considerations lead to a positive feedback loop between the search and advertiser sides. To see this, consider starting in a situation in which two platforms have equal numbers of searchers and advertisers. Now suppose platform 1 has an exogenous increase of 10 percent in search traffic with platform 2 holding steady. That will result in some advertisers joining platform 1 that had previously found it unprofitable to join either platform, and in some advertisers mounting campaigns on platform 1 that they had previously decided not to mount on either platform. Platform 1 now has more relevant ads for searchers. We would expect that some searchers would switch from platform 2 to platform 1. That, in turn, would increase the volume of advertising on platform 1. One could go through the same argument with an exogenous increase in advertising on the other platform. In both cases the effect of an advantage on one side becomes magnified as a result of the positive feedback effects.

Platform 1 obtains a further advantage as it obtains more advertisers. As a result of the keyword bidding system, an increase in advertisers may increase the bids on keywords. Consider first a situation in which we would expect the two platforms to secure identical CPCs. Platforms 1 and 2 have the same 20 bidders interested in 10 slots; the slots are as valuable on platform 1 as on platform 2; and the keyword auction is equally efficient in the sense of getting the bidders to reveal their highest values. In this case, we would expect the auction to result in the same bids for the same slots. Now suppose that the number of advertisers on platform 1 increases exogenously by two advertisers, while the number of advertisers on platform 2 is unchanged. If the new advertisers are situated similarly to the existing advertisers (for example, if they are all drawn from the same distribution), then it is likely that one of the new advertiser's optimal bid will place it in one of the top 10 slots. Suppose, for example, the new advertiser falls into the sixth slot. This has two main positive revenue effects for the platform. First, the new advertisers in slots 6 through 10 all have higher bids than before (because the new 10th place slot is taken by the advertiser previously in slot 9, and so on). With the higher bids come higher payments to the platform. The second effect comes from the new advertiser in slot 6 having a higher bid than the prior advertiser in slot 6 . This higher bid increases the bid of every advertiser in slots 1 through 5, because their optimal bids depend (positively) on the level of the bidder below them. ${ }^{44}$

\footnotetext{
${ }^{43}$ Maintaining an advertising campaign requires choosing the right keywords and fine tuning them, modifying bids, selecting the best landing pages, revising ad text, and monitoring account statistics such as clicks, impressions, CTR, average CPC, average position, and conversion rate.

${ }^{44}$ See Varian, supra note 18.
} 
All else equal, positive feedback effects would lead one ad search platform to achieve a monopoly position. ${ }^{45}$ The largest platform would always realize the highest CPC and provide the largest overall value to searchers and advertisers in the aggregate. The platform that provided the highest quality search engine for users and ad platform for advertisers would necessarily win the market. We would expect, though, that these positive feedback effects would diminish with the size of the platform. That is because the fixed costs become less important as the number of search queries expand, the value of additional bidders declines as the number of bidders increases, and more keywords have thick markets as the number of searchers expands.

\subsubsection{The role of rent extraction and ad placement}

Another difference between search-ad platforms concerns the revenue-per-search (RPS) they obtain for comparable search traffic and keyword bids. Platform 2 could realize a higher RPS than platform 1 even though both have the same amount of search and advertiser demand. That could happen if platform 2 was better at extracting value from advertisers due to having a more efficient keyword auction, or if platform 2 was better at predicting CTR, and therefore in maximizing revenue from page placement, or if platform 2 was able to deliver more relevant ads (and therefore better leads) that advertisers would pay more for. Together, these advantages would enable platform 2 to obtain a higher CPC for a given keyword and to obtain a higher CTR by offering more relevant ads to searchers. (We refer to this as an "RPS|S" advantage to denote that it is RPS controlling for size.)

Let us consider the implications of the RSP|Scale differences for the dynamic competition among platforms. One way for a smaller ad platform to catch up with a larger ad platform is to buy traffic. In fact, a substantial portion of Google's search ad traffic comes from third-party sites. AOL and Ask.com, the next largest search sites after Google, Yahoo, and MSN, use Google to supply paid search advertising results. Combined, they accounted for about 10 percent of search traffic in the United States among the top five search engines, compared to Google's 61 percent. ${ }^{46}$ Google, Yahoo, and Microsoft have bid for a number of these exclusive search contracts with third-party publishers. Google has won most of the head-on competition for which public data is available. For example, of the top 10 web sites that offer sponsored search results, and are not operated by firms that also own search engines, 8 use Google to provide paid search results. ${ }^{47}$

Consider the situation in which the only difference between two platforms is that platform 2 has more search traffic than platform 1. Moreover, RPS exhibits decreasing returns to scale so the RPS increases, because of the effect of advertisers being more willing to advertise on the larger platform, but eventually flattens out with respect to scale

\footnotetext{
${ }^{45}$ This is the classic tipping story for markets with indirect network effects. See Arthur (1996); Katz and Shapiro (1994). Tipping does not occur in many real-world markets as discussed in Evans and Schmalensee (2007b).

${ }^{46}$ Discussions with industry analysts suggest that 25 percent or more of Google's search ad revenue comes from partner sites.

${ }^{47}$ Web sites owned by Google, Yahoo, Microsoft and Baidu were not considered. The website aol.com was considered, even though Google owns a 5 percent stake in AOL. Similarly, mapquest.com, which is owned by AOL, was considered. The website ebay.com uses Google for paid search ad listings outside of the United States but uses Yahoo in the United States. Go.com also uses Yahoo. Lycos.com uses Ask.com, which in turn uses Google for paid search ad listings. Amazon uses its A9 search site, which uses Microsoft for search. Download.com uses Search.com. Search.com is a "meta" search site and includes unpaid search results from Google, Ask.com, Microsoft and others. The paid search ad results on Search.com are frequently referenced to Google and we have counted it among the publishers using Google.
} 
(RPS'(S) $>0$, RPS" $(S)<0$, and both eventually equal zero). ${ }^{48}$ Platform 2 has a higher RPS than platform 1 but platform 1 has a higher increase in RPS at its smaller size for any increase in search traffic. Then for sufficiently large increases in traffic, platform 1 will receive a larger increase in revenue than platform 2 and it will have an incentive to outbid platform 2. (For smaller increases in traffic, however, that increase taken alone, can be more valuable to the larger platform. ${ }^{49}$ ) More generally, platform 1 could potentially equalize its RPS with platform 2 if it can buy enough search traffic to eliminate the difference between the two. That would seem possible if the search queries are expanding over time and the RPS scale effect eventually vanishes. (Note, also, that the smaller platform could buy traffic by paying users of platform 2 to switch as opposed to entering into deals with publishers to carry its search tool bar.)

Now suppose that platform 2 receives a higher RPS at every level of search query traffic as shown in Figure 2. In this case, platform 2 has a bidding advantage over platform 1 at all sizes. Platform 1 can not achieve the same RPS by buying traffic. Moreover, if the difference between the curves is sufficiently large, platform 2 will continue to have an advantage even if the RPS curve flattens. Even if the smaller platform gets a greater increase in RPS from buying the same amount of traffic, it faces two disadvantages relative to the larger and more effective platform: (1) the value of the incremental traffic at the new RPS is still substantially lower than the other platform and (2) the value of the increase in RPS is applied to a smaller volume of existing traffic than for the larger platform.

It would seem difficult for a smaller platform to catch up with a much larger platform that has also has a substantial RPS advantage at every given scale.

\footnotetext{
${ }^{48}$ Revenue for the platform therefore shows increasing returns to scale but at a decreasing rate.

${ }^{49}$ For example, suppose the smaller platform had 10 searches with an RPS of 50 cents and the larger platform had 30 searches with an RPS of 100 cents and that an increase of 5 searches would increase the smaller platform's RPS to 70 cents and the larger platform's RPS to 105 cents. Even under these assumptions where the smaller platform gets a much larger increase in RPS, the increase in profits from getting the additional five searches is still larger for the large platform than the small one ( $\$ 6.75$ versus $\$ 5.50)$. In the long run, the smaller platform would also consider the aggregate benefits of accumulating additional traffic from multiple sources. The value of an increment in traffic comes not only from increasing its RPS on its existing traffic and the value of the new traffic, but also from the additional value that can result from future deals that increase its RPS on all of its traffic.
} 


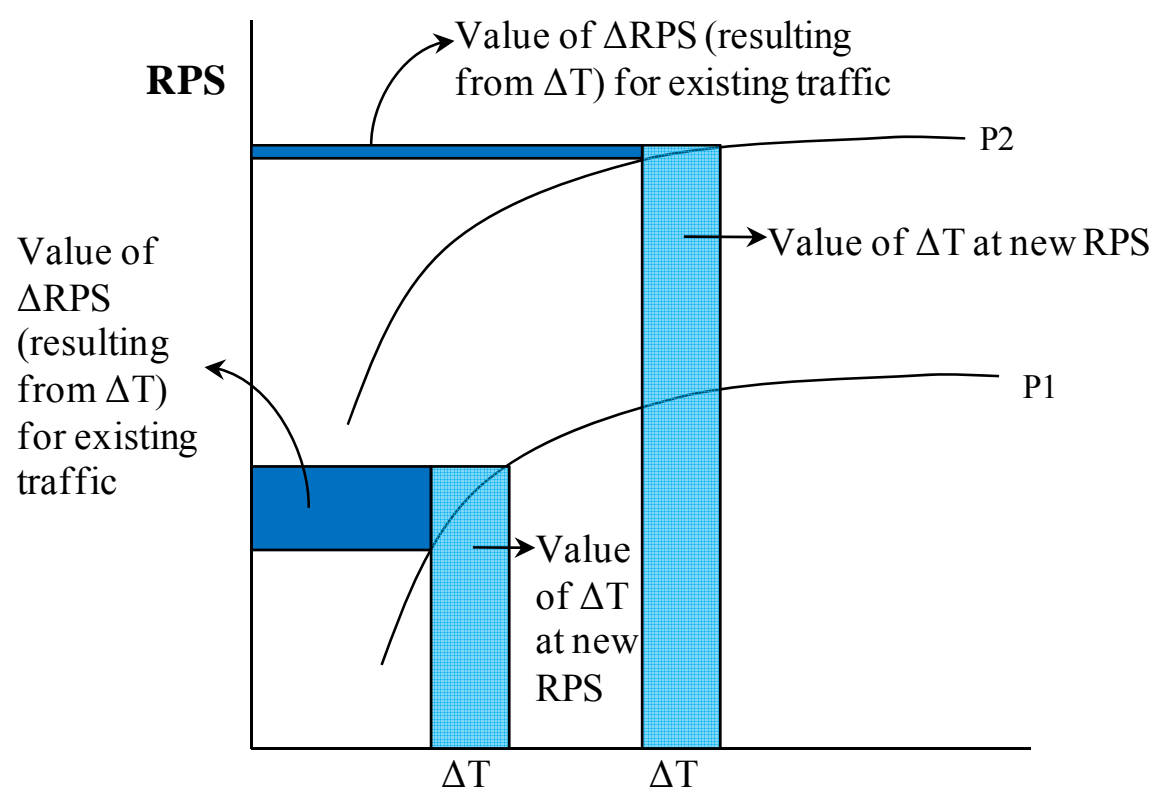

\section{Traffic volume}

\section{Figure 2. Value of incremental search traffic for high and low RPS platforms}

\subsubsection{Factors that work for and against winner-take-all competition}

A platform that secures a lead generates more positive feedback effects thereby increasing its lead. Smaller platforms can catch the larger platform in this case only if they are able to secure more traffic and can eliminate the RSP $\mid \mathrm{S}$ difference with the larger platform. As a practical matter, once the larger platform has captured most of the market, it is difficult for the smaller platform to catch up. Most traffic comes from an ad platform's own search site. To persuade users of the first-placed platform to switch, the second-placed platform has to offer sufficiently better search results to offset the superior advertising on the first-placed platform or pay them to induce them to switch. Likewise, to persuade advertisers to increase their use of the second-placed platform despite its having less traffic, it has to subsidize or otherwise lower their fixed costs of managing campaigns. Neither effort appears to be impossible, but both seem daunting.

The existence of positive-feedback effects does not, however, lead most multi-sided markets to converge to monopoly as observed by Evans and Schmalensee (2007b). Moreover, although firms secure quality advantages over each other in most real-world markets it does not appear that positive-feedback effects together with quality differences typically result in winner-take-all competition. Multiple competing platforms emerge when it is possible for smaller platforms to differentiate themselves from the leading platform, and from each other.

To see how such differentiation works in practice, it is useful to consider three close analogies to search-ad platforms. Most traditional media markets have multiple players. That results from market segmentation in which media firms aggregate particular kinds of consumers and sell access to these consumers to advertisers for whom those consumers are particularly valuable. The magazine industry has taken this to the greatest extreme as 
inspection of any magazine stand demonstrates. ${ }^{50}$ Financial markets have traditionally supported a few competing exchanges, although the move to electronic transactions has led to some consolidation. There is currently global competition among exchanges. Another two-sided market where we would expect monopolies is the yellow pages market. For most parts of the US, however, this is not the case. Although the local phone companies dominate some markets, private publishers have a significant presence in most markets. In particular, about 60 percent of submarkets have at least two yellow pages publishers, with roughly 25 percent of submarkets having more than two publishers. ${ }^{51}$

It remains to be seen whether ad search providers can differentiate enough to sustain a market structure that is not dominated by a single player. At this stage in the market evolution, it appears that search-based advertising is heading towards a single winner through some combination of positive feedback effects and RSP $\mid \mathrm{S}$ advantages. Google has increased its lead in search and advertisers each year since 2002. It has achieved a more than 75 percent share of search in 10 of the 15 countries for which data were analysed. ${ }^{52,53}$ The fact that it currently receives a CPC that is more than two times larger than its nearest rival also suggests that it has a significant RPS advantage over its rivals that enables it to bid more than its rivals for incremental traffic. ${ }^{54}$ In fact, Google has won most of the significant competitions to provide search toolbars or paid search listings on websites in the last couple of years, including a deal with AOL, one of the largest search sites of any significance besides Google, Yahoo and Microsoft, which operate their own search-ad platforms. ${ }^{55}$

These facts would suggest that the positive feedback and RPS $\mid \mathrm{S}$ effects for Google are significant. To coexist, competing platforms would have to narrow the scale differences, narrow any efficiency differences that lead to a higher RPS for a given scale, and differentiate themselves to compensate for remaining scale and efficiency disadvantages. Competing platforms could also grow and potentially overtake Google by creating superior

\footnotetext{
${ }^{50}$ For example Future, plc is a UK company that focuses on specialized magazines. These include Cross Stitcher, Guitarist, PC Gamer, Fast Car, Revolver, Mountain Biking UK, and Disney Girl.

${ }^{51}$ Rysman (2004).

${ }^{52}$ comScore (November 2007) "qSearch 2.0 Key Measures Report".

${ }^{53}$ The fact that Yahoo lost its lead in search is of course not consistent with a pure positive feedback explanation for Google's success.

${ }^{54}$ See supra note 37.

${ }^{55}$ Google also has deals with Fox, AOL, IAC and Dell. On August 7, 2006, Google and Fox Interactive Media entered into a multi-year contract making Google "the exclusive search and keyword targeted advertising sales provider for Fox Interactive Media". As part of the agreement, Google will pay Fox at least $\$ 900$ million so long as Fox is able to meet given traffic requirements and other commitments. See Google (7 August 2006) "Fox Interactive Media Enters Into Landmark Agreement with Google Inc."

http://www.google.com/press/pressrel/ir_20060807.html.

In December 2005, Google concluded a $\$ 1$ billion deal with AOL which among other things would allow "AOL... to sell additional ads for its search engine also [which is] powered by Google." See Olsen, S. and E. Mills (16 December 2005) "AOL to stick with Google," CNET News.com http://www.news.com/AOL-tostick-with-Google/2100-1030 3-5998600.html.

Google and IAC (the parent company of Ask.com) extended their sponsored search and advertising agreement in a move which is worth an estimated $\$ 3.5$ Billion to IAC over the next 5 years. See Fabrikant, G. (6 November 2007) "IAC/InterActive to Split Into 5 Companies," New York Times http://www.nytimes.com/2007/11/06/technology/06diller.html.
}

Dell also recently (May 2006) concluded a deal with Google which "means millions of Dell computers will leave the factories with Google software already installed on them." See BBC News (26 May 2006) "Dell deal bolsters Google search" http://news.bbc.co.uk/2/hi/technology/5019416.stm. 
search engines that provide more relevant results for users and superior advertising engines that, among other things, deliver more profitable sales to advertisers. Such improvements in quality on the two sides of the market may explain how Google was able to overtake Yahoo which was the initial leader in search-based advertising.

\section{$4 \quad$ Advertising on publisher websites}

Search results pages provide a large amount of advertising inventory which is primarily sold as text-based ads to advertisers. Many other web sites also supply advertising inventory as a result of having attracted traffic through content other than search results. ${ }^{56}$ Worldwide, there were over 19,000 websites that reached more than 0.05 percent of the estimated 810 million unique visitors on the Internet and could therefore also supply advertising inventory. ${ }^{57}$ These include traditional media companies such as The New York Times and CNN that have established online extensions, new media companies such as You Tube, blogs such as technorati.com, ${ }^{58}$ social network sites such as Facebook, and web portals that operate their own ad platforms including MSN and Yahoo. The ad inventory on these websites is often called "display" and often looks much like what one sees in print media. Unlike the suppliers of ad inventory on search results pages, the suppliers of display advertising inventory usually charge based on the cost-per-thousand viewers (CPM); that pricing model may change as discussed below.

The display advertising business has a complex business ecosystem. Unlike search which is based on an integrated two-sided platform that sits between the viewer and the advertiser, display advertising consists of several different platform models. These platform models differ according to the extent to which intermediation between the publisher and the advertiser is integrated into the publisher that supplies the inventory and the extent to which software tools that link advertisers and publishers are integrated into either the publisher that supplies the inventory or the intermediary between the publisher and the advertiser. The provision of advertising to viewers is therefore often provided by two or more interconnecting two-sided platforms. Section 4.1 provides an overview of the display advertising business. Section 4.2 describes the current market structure, including the role of different two-sided platforms. Section 4.3 looks at the prices and costs of display advertising. Section 4.4 discusses ways in which this industry, which is currently going through significant changes, may evolve.

\subsection{Overview of the online display advertising business}

Web publishers create advertising inventory by designing their web pages, which are written in HTML, to accept graphical, text, or video ads in various portions of the page. ${ }^{59}$ These portions of the page are reserved for ads and usually include code that permits the insertion of advertising on a real-time basis from various sources. Because of the necessary

\footnotetext{
${ }^{56}$ Search-engines are a special type of publishers. They use search result pages to attract viewers and then sell access to these viewers to advertisers.

${ }^{57}$ comScore (November 2007) "comScore MyMetrix report".

${ }^{58}$ Evans, D.S. (6 August 2007) "Economics of the Blogosphere," The Catalyst Code, http://www.thecatalystcode.com/theconversation/blog/2007/08/06/economics-of-the-blogosphere/.

${ }^{59}$ Web pages can also include languages such as JavaScript that generate HTML code when a page is called.
} 
coding, most websites do not change the space made available for ads frequently unlike newspapers, which can readily modify the layout for each print run. If they do not have an ad available to insert in a space they will often use the space for self-promotion. Figure 3 shows a typical layout of a page. Ad space is sold based on the length and width of the space in pixels; typical types of ads include banner ads at the top, skyscraper ads on the sides, and rectangle ads in various locations. As with traditional print advertising, some space is more valuable than others (top right vs. bottom left), some viewers are more valuable than others (18-49 vs. 50+), and some sites are more valuable than others (finance vs. entertainment news) in part because of the type of viewers they attract and in part because of what those viewers might be predisposed to purchase.

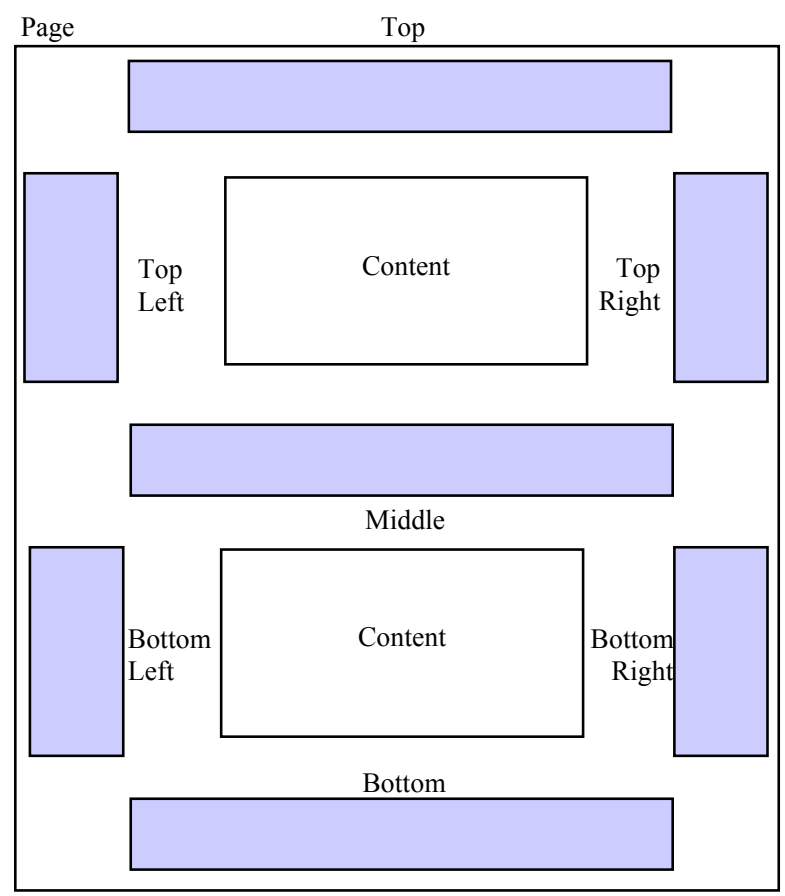

\section{Figure 3. Relative positioning of ads on a web page.}

The key technological difference between traditional display advertising and online display advertising involves the ability to target ads to particular consumers in real time. In the traditional advertising industry, targeting is primarily accomplished through the development of media that use content to attract particular socioeconomic and demographic groups (from broad groups such as people between 29 and 55 to narrow groups such as fly fishermen). Traditional advertisements are seen by all viewers of the media containing the ad. Online advertising makes it possible to serve an advertisement specifically for the viewer of the web page based on knowledge of the viewer's socioeconomic characteristics or even what sorts of products the viewer is considering purchasing.

Online advertisers and publishers currently engage in targeting to a relatively modest degree. An advertiser will buy the front page of Yahoo, which is not that different from buying advertising on a television show - the advertiser is interested in reaching those audiences but is not targeting beyond that. Many of the investments currently made in online advertising (including the purchases of ad networks and ad serving and behavioral 
targeting providers), however, reflect a belief that more sophisticated targeting will become increasingly important.

Unlike traditional advertising, online ads can use the IP address of the computer that has signed on to the website to focus on narrow geographic areas including ones with particular socioeconomic characteristics. Publishers also have the ability to determine what ads viewers have seen recently on their sites and limit duplicate messages. They can also determine what content the user has recently been interested in - for example, an auto advertiser may be interested in reaching viewers who have recently looked at the auto reviews, but with online advertising, these viewers can be shown ads not only on the auto section but on other content pages they may be viewing. Viewers for whom the publisher has registration or other identifying information offer further targeting opportunities. Contextual advertising platforms, as discussed below, provide some additional targeting by considering whether certain keywords such as "luxury hotels London" occur on the web page. It is expected, however, that online advertising will increasingly make greater use of viewer data - whether actual or inferred - to better target more ads to viewers and thereby make online advertising more effective for advertisers. We discuss such "behavioural targeting" below in examining future developments in the online advertising business.

Like all sellers and buyers, publishers and advertisers require ways to identify optimal trading opportunities and to establish transaction prices. There are two major ways that this "intermediation" occurs. First, it can occur directly through bilateral exchanges between publishers and advertisers. eBay, for example, may sell Nokia the right to present an advertisement in a particular spot to viewers with specific characteristics by having its sales agents deal directly with Nokia's buying agents. Second, it can occur indirectly through multilateral exchanges between publishers and advertisers using advertising networks. Hearst Publishing may sell ValueClick - an advertising network - advertising inventory from its various online newspaper and magazine properties. ValueClick may then sell advertisers access to particular kinds of viewers by pooling relevant advertising inventory from Hearst and other publishers. In this case, the advertiser buys access to a type of viewer - for example "fashion conscious young women in upscale locations" - but is not necessarily guaranteed that it will reach these women on Hearst's Cosmopolitan website.

The extent to which advertisers and publishers use direct and indirect methods of distribution for advertising varies. Smaller publishers and advertisers typically rely only on indirect methods because it is not economical to carry the cost of salespeople and purchasing agents. Larger publishers and advertisers - which account for the preponderance of online display advertising sales - often use both direct and indirect methods. Larger publishers use direct methods to sell their premium space - such as the space on the first web page and high quality space on some of the interior web pages - and this space is then said to be "reserved" for an advertiser. They also use indirect methods to lower quality space such as the bottom space on interior pages, or advertising inventory that has not been reserved either because there was an unexpected spike in viewership which increased the supply of inventory, or because they did not sell all of their advertising inventory at the prices sought in direct sales. Advertising inventory that has not been reserved is sometimes called "remnant". We discuss the relative pricing and use of directly and indirectly sold online advertisements below.

Advertisers and publishers rely on various services which they either provide themselves or purchase from others. Large advertisers and advertising agencies often 
license an advertising package such as aQuantive's AdManager. ${ }^{60}$ They typically manage advertising on hundreds of websites and across numerous products using many methods of online advertising. The advertising software helps them manage these various campaigns and instructs the server to deliver advertising copy downstream into available inventory.

Large publishers usually license a publisher tool such as DoubleClick's DART for Publishers (DFP). ${ }^{61}$ Publisher tools are highly sophisticated software programs. They are usually integrated into many other aspects of the website technology and business practices. The publisher hard codes links to the publisher tool to fill the ad space for which it wants to use the management, reporting, and serving capabilities of the publisher tool. When a viewer clicks on a web page the publisher tool makes a decision, based on preprogrammed rules, as to which ad to present to the viewer. The publisher tool checks whether the particular ad space that the viewer is about to see has been "reserved", and if not, whether there is an ad network that can fill that inventory space. The publisher tool then retrieves the chosen ad, or directs the advertiser or ad network's server to retrieve the ad, which is then shown to the user. This entire process happens in the blink of an eye. A few very large publishers rely on publisher tools they have developed themselves rather than licensing a publisher tool from a third party.

Publishers also use a variety of advertising networks for indirectly sold advertisements as we discuss below.

\subsection{Market structure for advertising on publisher websites}

The online display advertising business consists of several types of two-sided platform businesses. Some platforms integrate features of the other platforms as we will see below.

- Publishers supply content on their websites that attracts viewers and sell the resulting advertising inventory to advertisers directly or indirectly.

- Advertising networks serve as intermediaries between publishers and advertisers by aggregating the demand and supply of advertising inventory. (Other intermediaries such as third-party sales representative also operate two-sided intermediation platforms.)

- Advertising software tool companies usually supply both software tools for publishers and software tools for advertisers; they at least try to generate positive feedbacks between the publisher and advertiser side.

Table 5 lists the top two firms in each of these categories and estimates of their revenues.

\footnotetext{
${ }^{60}$ See Atlas Solutions (2008) “Atlas Advertiser Suite,” http://www.atlassolutions.com/services.aspx and DoubleClick (2008) “DART For Advertisers,” http://www.doubleclick.com/products/dfa/index.aspx.

${ }^{61}$ See DoubleClick (2008) “DART For Publishers,” http://www.doubleclick.com/products/dfp/index.aspx.
} 


\begin{tabular}{|c|l|}
\hline & 2006 Revenue (M) \\
\hline Publishers (Display Advertising) & \\
\hline Yahoo & $\$ 1,158$ \\
\hline Time Warner / AOL & $\$ 1106$ \\
\hline Microsoft Network & $\$ 939$ \\
\hline New York Times / About.com & $\$ 240$ \\
\hline Advertising Networks & \\
\hline Google & $\sim \$ 1,500$ \\
\hline Advertising.com & $\$ 455$ \\
\hline ValueClick & $\$ 383$ \\
\hline Right Media & $\$ 150$ \\
\hline Tool Providers & \\
\hline DoubleClick & $\sim \$ 300$ \\
\hline 24/7 Real Media & $\$ 200$ \\
\hline Atlas & $\$ 122$ \\
\hline
\end{tabular}

\section{Table 5. Leading Publishers, Advertising Networks and Tool Providers}

Note: Rankings and revenues of publishers are for the United States only. All other rankings and revenues are based on worldwide data. The figures for publisher revenue are industry estimates. Google does not report contextual revenue publicly. The given figure is a rough estimate based on discussions with industry experts. The revenue number for ValueClick is for the company's Media segment, which includes Display Advertising, Lead Generation Marketing, Email Marketing and E-commerce, so the display ad revenue may be somewhat overstated. The revenue figures for DoubleClick and 24/7 RealMedia are for the respective companies' entire revenues, including but not necessarily restricted to revenue from the provision of software tools. Atlas' revenue figure is from aQuantive's 'Digital Marketing Technologies (DMT)' segment. In its annual report, aQuantive states that "[o]ur DMT segment consists of Atlas, a provider of digital marketing technologies and expertise." Source: Publishers' revenues are based on Casale Media Inc. (2007); Google's revenue is based on Google's SEC Filing (2006) "Form 10-K"; Advertising.com's revenue is from Time Warner's SEC Filing (2006) "Form 10-K" (Advertising.com is a wholly owned subsidiary, and generates one third of AOL's advertising revenue); ValueClick's revenue comes from ValueClick's SEC Filing (2006) "Form 10-K"; Right Media's revenue comes from Sloan, P. (3 April 2007) "The Quest for the Perfect Online Ad," CNNMoney.com http://money.cnn.com/magazines/business2/business2_archive/2007/03/01/8401043/index.ht m?postversion=2007040309; DoubleClick's revenue comes from Story, L. and M. Helft (14 April 2007) “Google Buys an Online Ad Firm for \$3.1 Billion," New York Times http://www.nytimes.com/2007/04/14/technology/14deal.html?ex=1334203200\&en=d94eb7f $788 \mathrm{~b} 32 \mathrm{db} 5 \& \mathrm{ei}=5090 \&$ partner $=$ rssuserland\&emc $=$ rss; 24/7 Real Media's revenue is based on 24/7 Real Media's SEC Filing (2006) "Form 10-K"; Atlas' revenue is based on aQuantive's SEC Filing (2006) "Form 10-K."

Online publishers in turn come in three variations.

- $\quad$ Large integrated online publishers have their own publisher software tools for operating their websites. In addition to their direct sales forces, they also have advertising networks that sell their non-reserved inventory to advertisers. 
- $\quad$ Large nonintegrated publishers have their own direct sales forces. However, they usually license a third-party publisher tool and work with one or more third-party advertising networks to sell their non-reserved inventory to advertisers.

- Small nonintegrated publishers typically do not have their own direct sales forces. They usually rely on an advertising network that has its own publisher tools. Once they paste a direction to that advertising network in their advertising space, they need do nothing more.

Detailed data on the sales of these three types of publishers is not available. However, discussions with industry experts suggest that the substantial majority of display ad revenue is from ads placed on the first two types of publishers. The largest publishers AOL, MSN and Yahoo - are integrated, fall under the first category, and collectively account for ad revenue that is likely of the same order of magnitude as the nonintegrated publishers.

There are two major kinds of advertising networks.

- Contextual ad networks use the same software that they use for managing their search-based advertising campaigns to manage their contextual-based advertising campaigns. Advertisers use this software to bid on keywords on the publishers that rely on the contextual network. The contextual ad network then inserts ads provided by the advertiser on those websites based on the advertiser's bid and the content of the sites on its network. ${ }^{62}$ Advertisers also have some ability to select inventory based on the website or based on various characteristics of users.

- Most online networks do not use contextual targeting. These standard online advertising networks specialize in aggregating advertising inventory from a variety of publishers that corresponds to some group for which there is demand from advertisers. They then sell advertisers the ability to present their ads to some number of viewers in that group without necessarily guaranteeing that the ads will be seen on any particular site. As mentioned below, some of these ad networks are using behavioral targeting techniques to deliver more relevant ads for viewers and advertisers.

Table 5 lists the leading advertising networks worldwide. Google operates by far the largest contextual advertising network and has the largest advertising network overall, with ad revenues that are likely three times those of its next closest competitor in 2006. Other leading firms include Advertising.com with revenue of $\$ 455$ million is 2006, and ValueClick with revenue of $\$ 383$ million in 2006. A number of even smaller competitors, such as Tribal Fusion, BlueLithium, Quigo and Tacoda are not publicly traded and financial data on their ad revenues are not available.

Finally, the leading software tools providers make tools for both publishers and advertisers even though these tools are in some sense very different software. They have at least attempted to persuade publishers and advertisers that they would benefit from their tools because the other side of the market is using those tools. On the DART for Publishers web page, for example, DoubleClick states ${ }^{63}$ :

\footnotetext{
62 The contextual platforms also used other characteristics for targeting in addition to content.

${ }^{63}$ See DoubleClick (2008) “DART For Publishers" http://www.doubleclick.com/products/dfp/index.aspx.
} 
"Our position at the center of the digital media landscape means we can deliver unparalleled buyer/seller integration, including zero discrepancies on ads trafficked from DoubleClick's DART for Advertisers solution to its DART for Publishers solution. This puts money directly into your pocket and simplifies billing and reconciliation."

A key development in 2007 was that the leading software tool providers were purchased by other platforms. Google bought DoubleClick, Microsoft bought aQuantive, and WPP a large advertising agency - bought 24/7 RealMedia. DoubleClick is generally regarded as the largest tools provider, ${ }^{64}$ especially for major publishers. Table 5 lists the leading tools providers worldwide. In 2006, DoubleClick had revenue of about $\$ 300$ million. Tools providers not listed in the table include MediaPlex and ValueClick.

There is a close relationship between the form of intermediation used by publishers and their use of publisher tools and advertising networks. Publishers that want to sell directly must have a third-party publisher tool or provide their own software. Publishers that want to sell some space indirectly must use an advertising network. Comprehensive data are not available on the portion of directly and indirectly sold advertising inventory. Advertisers and publishers I have talked to, however, seem to agree that somewhere around 70 percent of advertising revenue for large publishers is the result of direct sales and the remaining 30 percent of advertising revenue is the result of indirect sales through contextual or traditional advertising networks. Because indirectly sold ad inventory is much cheaper than directly sold ad inventory, the advertising networks account for a higher percentage perhaps around 50 percent - based on the number of "impressions" (the viewers that see an ad). However, some individuals in the industry put the direct sales figure as high as 95 percent of revenue for large publishers.

\subsection{Prices and costs for online display advertising}

Most online display advertising inventory, on a revenue basis, is bought and sold on the basis of CPM. The prices paid by advertisers varied from less than $\$ 1$ to more than $\$ 100$ as of early 2007. Where the price falls in this range depends on the interplay of the location of the advertising inventory on the web page and the website; the amount of space measured in pixels; the characteristics of the viewers; and the type of intermediation used. As is common in business-to-business transactions, large publishers often engage in individual negotiations with advertisers and discount prices off of a rate card. The contextual ad networks typically charge advertisers on a CPC basis which is determined from the keyword bidding process. Not surprisingly, large publishers receive payments that are in the same range as for advertising networks for the same amount of space (three or four contextual ads typically appear in the same space), on the order of \$2 CPM.

The publishers have to pay for intermediation services when they are not using a direct sales force to sell the ad. Google, the leading contextual network, is believed to keep about 15-20 percent of advertiser revenues. ${ }^{65}$ The standard advertising networks typically keep

\footnotetext{
${ }^{64}$ See Moresco, J. (19 December 2007) “Microsoft, Viacom Gird Against Google,” RedHerring.com http://www.redherring.com/Home/pages/print/posts/?bid=28262ee6-7dba-4f55-bb53cd1a4e1d52c0\&mode=Full.

${ }^{65}$ Across all of Google's partner traffic, including both contextual and search, in the 12 months from Q4 2006 to Q3 2007, Google retained a 16 percent share. This share likely varied by type of traffic and publisher. See Google SEC Filing (2006) "Form 10-K"; See Google SEC Filing (2007) "Form 10-Q" for the quarterly period ended September 30, 2007. To the extent the percentage retained differs significantly between search and contextual, this figure may over or understate.
} 
20 percent or more, although the negotiations are highly individualized. ${ }^{66}$ The tool providers also impose a transaction cost on the buying and selling of advertising inventory. In all cases, the advertising networks keep a portion of the revenue they receive from advertisers as a commission. For directly sold ads, the publisher tools provider will usually charge about 5 cents per thousand impressions served and the advertiser tool provider about 7-8 cents per thousand impressions.

\subsection{Market evolution}

For large publishers, the online display advertising business does not look much different than the traditional advertising business but for the fact that space can be customized for each viewer. A large fraction of the revenues come from old-fashioned selling of ads by hand. And even for space that is not reserved the ad networks are not much different economic beasts than the American ad agency created in 1841 that bought space from publishers which it resold to advertisers. Several developments could dramatically alter this business.

The first involves the use of computerized matching, clearing, and settlement of transactions between advertisers and publishers. The advertising networks currently do much of this work through human effort - they call publishers and advertisers. Some exchanges have been launched, which provided an electronic exchange between advertisers and publishers. A few exchanges also connect advertising networks to facilitate the trading of excess supply and demand between them. These exchanges face several challenges. Online advertising space is highly heterogeneous. Matching supply and demand is therefore a technically challenging exercise. Moreover, these exchanges would face the usual challenge of securing sufficient liquidity to have thick enough markets for potentially narrowly defined inventory. ${ }^{67}$ However, they also have the opportunity to reduce what appear to be rather high transaction costs for buying and selling advertising inventory. Based on the figures reported above, the transactions costs incurred by large publishers and advertisers is of the order of 20 percent or more of the sales price after the ad networks and publisher tool providers are taken into account. That is much higher than intermediation costs in other industries - 0.1-1.7 percent for financial exchanges ${ }^{68}$ and as little as 1-2 percent for some real estate transactions. ${ }^{69}$

The second development increases the value of electronic exchanges and therefore could help these exchanges achieve a critical mass of liquidity. Data-intensive behavioral targeting can significantly increase the likelihood that an ad will reach a consumer to whom that ad is relevant and who is likely to translate into a sale for the advertisers. As this technology improves the value of selling ads through automated processes rather than through direct selling would increase. This sophisticated targeting faces at least two

\footnotetext{
${ }^{66}$ In discussions with industry experts, I have heard that the share retained by the ad network may be as high as 50 percent in some cases. Typically, the ad network offers the publisher a fixed CPM guarantee and retains whatever increment it can sell the inventory for.

${ }^{67}$ These are B2B exchanges. We know from the dramatic collapse of B2Bs in the early 2000s that obtaining liquidity, especially from the supply side (publishers in the case of online advertising) is the most serious challenge. See Silicon.com (23 January 2002) "B2B exchanges - What happens now?"; Ward, H. (29 November 2001) "B2B exchanges fail to deliver," Computer Weekly; Tedeschi, B. (7 May 2000) "Investing; How Killer B-to-B's Went Into A Tailspin," New York Times.

${ }^{68}$ Data are for 2004. See European Commission (2006) "Competition in the EU securities trading and posttrading-Issue paper."

${ }^{69}$ Data are for 2002-04. See Office of Fair Trading (2004) "Estate agency market in England and Wales".
} 
challenges. The first is that it is technologically difficult to process the relevant data and serve the advertisement so that it is part of the web page when the viewer first looks. The second is that behavioral targeting relies on extensive personal information the use of which has drawn increased scrutiny by regulators and the media. ${ }^{70}$ Online advertising companies currently collect and store significant data through the insertion of cookies on personal computers and other techniques. It is possible that these activities will be curtailed.

The market structure that would result from these developments would have one or more advertising platforms sitting between publishers and advertisers. Trading platforms typically have significant scale economies and positive feedback effects. That results in a small number of viable players. In the case of financial exchanges, the globalization of markets combined with the development of electronic trading has led to consolidations and increased concentration. Several factors suggest that there would be stronger forces leading to the emergence of a single advertising platform than has been the case for financial exchanges. First, behavioral targeting requires the use of historical information on consumers often pulled from their past behavior as observed by the advertising platform. Larger platforms could secure advantages that would be hard for smaller platforms to replicate. Second, behavioral targeting may have some of the long-tail effects that have given large search platforms advantages. As the supply and demand is sliced more finely, larger platforms have thicker markets in every niche. Third, effective behavioral targeting is likely to require significant technical advances as well significant computer capacity. The IP rights in particular could establish barriers to smaller players.

Winner-take-all competition stories, however, tend to work better in theory than in practice in many industries. While it seems implausible that there will be many commercially significant advertising platforms, two factors identified in the multi-sided platform literature could lead to several viable platforms. The first is whether it is possible for advertising platforms to differentiate themselves sufficiently from their rivals from the standpoint of advertisers or publishers while maintaining sufficient liquidity. The second concerns the extent to which advertisers or publishers can multi-home. There would not appear to be any obstacles to advertisers using multiple advertising platforms. Publishers currently rely on their publisher tools to multi-home with multiple alternative channels. If publisher tools become integrated into the advertising platform the ability to multi-home is likely to decline, thereby reducing competition (except for exclusives) at the advertiser level.

The development of advertising platforms for trading ads and eyeballs would alter market structure in the publishing industry as well. Most online and offline media companies are vertically integrated into selling advertising. They have their own sales forces which, for the larger publishers, sell the bulk of advertising. As advertising

\footnotetext{
${ }^{70}$ The FTC has heard privacy cases against several web properties, including the online advertiser ValueClick, which was ordered in March 2008 to pay a fine of \$2.9 million "to settle Federal Trade Commission charges that its advertising claims and e-mails were deceptive and violated federal law". See Federal Trade Commission (17 March 2008) "ValueClick to Pay \$2.9 Million to Settle FTC Charges" http://www.ftc.gov/opa/2008/03/vc.shtm. The FTC has also published a report on privacy issues: Federal Trade Commission (March 2008) "Protecting Consumers in the Next Tech-ade: A Report by the Staff of the Federal Trade Commission" http://www.ftc.gov/os/2008/03/P064101tech.pdf. Further, there have been moves towards legislation in the states of New York and Connecticut that would restrict the use of personal information for online advertising. See Story, L. (20 March 2008) "A Push to Limit the Tracking of Web Surfers' Clicks," New York Times http://www.nytimes.com/2008/03/20/business/media/20adco.html.
} 
platforms evolve, publishers may specialize in attracting content and leave the advertising business to the platforms. Many small publishers now do just that.

\section{$5 \quad$ Concluding remarks}

Internet-based technologies are revolutionizing the stodgy $\$ 625$ billion global advertising industry. Advertisers once had only crude methods available for targeting their ads to consumers who were likely to buy their products. That was done mainly by selecting advertising media - such as particular television shows or magazines - that specialized in the relevant audiences. Advertisers also had little information on who actually watched their ads and what activities followed. The Internet has changed that by allowing advertisers to target specific individuals and pay only when those individuals click on the ads. More sophisticated technologies are beginning to track not only whether individuals clicked on an ad but whether that actually translated into a sale. Search-based advertising has developed the most advanced methods for targeting consumers and charging for results. Display based advertising is catching up.

These new technologies are critically important for understanding the evolution of the advertising business because it is expected that more advertising will take place online. Web-based businesses are providing more content and services that people want to spend time viewing. The number of Internet users worldwide increased from 741 million in December $2006^{71}$ to 816 million in December $2007 .^{72}$ Younger people, in particular, are spending more time on social networking sites such as Facebook and online gaming sites such as Second Life.

In addition, more of the devices that people use for consuming content will have an Internet connection in the future. More than one billion PCs will be in use worldwide by the end of $2008 .^{73}$ There are three billion mobile phone subscribers worldwide and nearly two billion smart phones in use. ${ }^{74}$ An increasing portion of those mobile phones will have internet connections and browsers as does the iPhone. It is expected that many televisions will have Internet connections as well. ${ }^{75}$ Other devices may have internet connections as well. Amazon's e-book reader has an always-on wireless feature that would enable it to deliver targeted ads.

Finally, many of the advertising-supported web-based platforms have encouraged developers to write applications that work with their platforms. These applications may also carry advertising. For example, Google has encouraged developers to write applications using Google Maps but has reserved the right to insert advertisements into those applications. ${ }^{76}$

These changes are important for understanding the current structure and evolution of the online advertising business. They are also critical for numerous public policy issues

\footnotetext{
${ }^{71}$ comScore (June 2007) "comScore MyMetrix Custom Media Trend Report".

${ }^{72}$ comScore (December 2007) “comScore MyMetrix Key Measures Report”.

${ }^{73}$ See Yates (2007).

${ }^{74}$ Associated Press (7 January 2008) "Yahoo revs up mobile phone - Plan hopes to attract new users, more ads," The Star-Ledger; Duerden, A. (1 October 2007), "CIOs On The Back Foot Over Handheld Device Security," The Banker.

${ }^{75}$ See Stelter, B. (16 April 2008) "TV, but With Connections," New York Times http://tvdecoder.blogs.nytimes.com/2008/04/16/tv-but-with-connections/.

${ }^{76}$ See Google (16 April 2007) “Google Terms of Service” http://www.google.com/accounts/TOS.
} 
that have emerged. Will a single ad platform emerge or will several remain viable? What are the consequences of alternative market structures for ad platforms for a web economy that is increasingly based on selling eyeballs to advertisers? Data is central to these ad platforms. Historically, communication providers such as the telephone companies have been highly respectful of privacy rights. The ad platforms have business models that are based on collecting and hoarding highly personal data from individuals. The implications of that have not been fully thought through by either consumers or policymakers.

\section{$6 \quad$ References}

Anderson, S.P. and S. Coate (2005) "Market Provision of Broadcasting: A Welfare Analysis," Review of Economic Studies, 72: 947-972.

Anderson, S.P. and J.J. Gabszewicz (2006) "The Media and Advertising: A Tale of TwoSided Markets," in V.A. Ginsburgh \& D. Throsby (ed.), Handbook of the Economics of Art and Culture. North-Holland: The Netherlands.

Arthur, B. (1996) "Increasing Returns and the New World of Business," Harvard Business Review, 74: 100-109.

Bagwell, K. (2007) "The Economic Analysis of Advertising," in M. Armstrong \& R. Porter (ed.), Handbook of Industrial Organization, 3: 1701-1844, North-Holland: Amsterdam.

Battelle, J. (2005) The Search: How Google and Its Rivals Rewrote the Rules of Business and Transformed Our Culture. Penguin Group: New York.

Bear Stearns (2007) "Not Out of the Woods But A Step in The Right Direction." 17 October.

Casale Media Inc. (2007) "Digital Marketing and Media Fact Pack: A Supplement to Advertising Age." 23 April.

Cho, M., A. Iskandar, S. Kidambi, S. Shepherd and C. Vuong (2005) "Search-based Online Advertising," Working Paper, available at people.ischool.berkeley.edu/ hal/Courses/StratTech07/Tech/Tech05/C-report.doc.

Dai, H. K., Z. Nie, L. Wang, L. Zhao, J-R. Wen, and Y. Li (2006) "Detecting Online Commercial Intention," World Wide Web Conference, Edinburgh, Scotland.

Economides, N. (1993) "Network Economics with Application to Finance," Financial Markets, Institutions \& Instruments, 2: 89-97.

Edelman, B., M. Ostrovsky and M. Schwarz (2007) "Internet Advertising and the Generalized Second Price Auction: Selling Billions of Dollars Worth of Keywords," American Economic Review, 97: 242-259. 
Eisenmann, T. (2007) "The Economics of Internet Advertising: Implications for the Google-DoubleClick Merger," Presentation for AEI-Brookings Joint Center. July.

Evans, D.S., F.M. Fisher and J.J. McGowan (1980) "The Audience Revenue Relationship for Local Broadcast Stations," Bell Journal of Economics, 11: 694-708.

Evans, D.S. and R. Schmalensee (2007a) Catalyst Code: The Strategies of the World's Most Dynamic Companies. Harvard Business School Press: Massachusetts.

Evans, D.S. and R. Schmalensee (2007b) "The Industrial Organization of Markets Based on Two-Sided Platforms," Competition Policy International, 3: 151-179.

Garbade, K.D. and W.L. Silber (1979) "Structural Organization of Secondary Markets: Clearing Frequency, Dealer Activity and Liquidity Risk," The Journal of Finance, 34:577593.

Hallerman, D. (2006) “Search Marketing: Players and Problems,” eMarketer, April.

Hallerman, D. (2007) “Search Marketing: Counting Dollars and Clicks,” eMarketer, April.

Hallerman, D. (2008) "US Online Advertising: Resilient in a Rough Economy," eMarketer, March.

Interactive Advertising Bureau (2003) "IAB Internet Advertising Revenue Report: A Quarterly Survey Conducted by PricewaterhouseCoopers and Sponsored by the Interactive Advertising Bureau (IAB): 2002 Full-Year Results" http://www.iab.net/media/file/resources adrevenue pdf_IAB PwC_2002final.pdf

Interactive Advertising Bureau (2004) "IAB Internet Advertising Revenue Report: A Quarterly Survey Conducted by PricewaterhouseCoopers and Sponsored by the Interactive Advertising Bureau (IAB): 2003 Full-Year Results" http://www.iab.net/media/file/resources adrevenue pdf_IAB_PwC 2003.pdf

Interactive Advertising Bureau (2005) "IAB Internet Advertising Revenue Report: An Industry Survey Conducted by PricewaterhouseCoopers and Sponsored by the Interactive Advertising Bureau (IAB): 2004 Full-Year Results" http://www.iab.net/media/file/resources adrevenue pdf IAB PwC 2004full.pdf

Interactive Advertising Bureau (2006) "IAB Internet Advertising Revenue Report: An Industry Survey Conducted by PricewaterhouseCoopers and Sponsored by the Interactive Advertising Bureau (IAB): 2005 Full-Year Results" http://www.iab.net/media/file/resources adrevenue pdf IAB PwC 2005.pdf

Interactive Advertising Bureau (2007) "IAB Internet Advertising Revenue Report: An Industry Survey Conducted by PricewaterhouseCoopers and Sponsored by the Interactive Advertising Bureau (IAB): 2006 Full-Year Results" http://www.iab.net/media/file/resources adrevenue pdf IAB PwC 2006 Final.pdf 
Katz, M. and C. Shapiro (1994) "Systems Competition and Network Effects." Journal of Economic Perspectives, 8: 93-115.

Kaye, B.K. and N.J. Medoff (2001) Just A Click Away: Advertising on the Internet. Massachusetts: Allyn and Bacon.

Lehman Brothers (2007) "Internet Data Book," April.

Minton, S. (2007) "Worldwide Telecom Spending 2007-2011 Forecast: Worldwide Telecom Black Book, 2007," IDC.

Rochet, J. and J. Tirole (2003) "Platform Competition in Two-Sided Markets," Journal of the European Economic Association, 1: 990-1029.

Rysman, M. (2004) "Competition Between Networks: A Study of the Market for Yellow Pages," Review of Economic Studies, 71: 483-521.

Schwarz, M. and K. Sonin (October 2005) "Efficient Actions in a Dynamic Auction Environment," Working Paper http://rwj.berkeley.edu/schwarz/publications/Schwarz\%20Efficient\%20Actions.pdf

Varian, H.R. (2006) "Position Auctions," Working Paper, University of California, Berkeley.

Yates, S. (2007) "Worldwide PC Adoption Forecast, 2007 to 2015," Forrester Research. http://www.forrester.com/Research/Document/Excerpt/0,7211,42496,00.html 